RICARDO TAKIY SEKIGUCHI

\title{
AVALIAÇÃO CLÍNICA DO CRESCIMENTO GENGIVAL INDUZIDO POR CICLOSPORINA-A E TACROLIMUS EM INDIVÍDUOS TRANSPLANTADOS RENAIS: ESTUDO PROSPECTIVO
}




\section{Ricardo Takiy Sekiguchi}

Avaliação clínica do crescimento gengival induzido por

Ciclosporina-A e Tacrolimus em indivíduos transplantados renais: estudo prospectivo

Dissertação apresentada à Faculdade de Odontologia da Universidade de São Paulo, para obter o título de Mestre, pelo Programa de Pós-Graduação em Odontologia.

Área de Concentração: Periodontia

Orientador: Prof. Dr. Roberto Fraga Moreira Lotufo 


\section{FOLHA DE APROVAÇÃO}

Sekiguchi RT. Avaliação clínica do crescimento gengival induzido por ciclosporina-A e tacrolimus em indivíduos transplantados renais: estudo prospectivo [Dissertação de Mestrado]. São Paulo: Faculdade de Odontologia da Universidade de São Paulo; 2006.

São Paulo, / / 2006

\section{Banca Examinadora}

1) $\operatorname{Prof}(a) . \operatorname{Dr}(a)$.

Titulação:

Julgamento:

Assinatura:

2) $\operatorname{Prof}(a) . \operatorname{Dr}(a)$.

Titulação:

Julgamento:

Assinatura:

3) $\operatorname{Prof}(a)$. Dr(a).

Titulação:

Julgamento:

Assinatura: 


\section{DEDICATÓRIA}

Aos meus queridos pais, KINJIRO SEKIGUCHI e NATALIA TAMIKO SEKIGUCHI, com todo amor, admiração e gratidão pelo apoio ao longo de toda minha formação. Saibam que não há ciência, não há graduação, mestrado ou afins que possam ensinar os valores e princípios que vocês me deixaram como herança. Essa lição, podem ter certeza, nunca será esquecida. Muito obrigado.

Aos meus irmãos, FÁBIO e LARA, pela compreensão que vocês tiveram neste período bastante difícil.

Aos Professores da Disciplina de Periodontia da Faculdade de Odontologia da Universidade de São Paulo, pela amizade e convivência científica compartilhada. 


\section{AGRADECIMENTOS ESPECIAIS}

Ao Prof. Dr. ROBERTO FRAGA MOREIRA LOTUFO, mais que meu orientador, um grande amigo para todos os momentos. Obrigado pelo incentivo e apoio durante o desenvolvimento deste trabalho.

À Profa. Dra. LUCIANA SARAIVA e à profa. LUCIANA SAFIOTI, pela confiança depositada e pelo apoio que foi fundamental para a realização deste trabalho.

Ao Prof. Dr. CLÁUDIO MENDES PANNUTI, não apenas pela ajuda na análise e interpretação estatística, mas por todas as contribuições e sugestões durante o estudo.

Ao Prof. Dr. GIUSEPPE ALEXANDRE ROMITO, por toda colaboração na realização deste trabalho.

À Dra. ROSANA GERAB TRAMONTINA, pela dedicação e paciência durante o desenvolvimento do projeto de iniciação científica, que me impulsionou para o curso de mestrado.

Muito obrigado. 


\section{AGRADECIMENTOS}

Ao Prof. Titular FRANCISCO EMíLIO PUSTIGLIONI, pelo incentivo e dedicação durante todo o curso.

Aos Professores da Pós-Graduação, GIORGIO DE MICHELI, LUIZ ANTONIO PUGLIESE ALVES LIMA.

Aos Professores da Graduação, SILVIA ROSANA CARNEIRO SOARES, MARCO ANTONIO PAUPÉRIO GEORGETTI, KOTO NAKAE, CESÁRIO ANTÔNIO DUARTE, ANA VITÓRIA IMBRONITO, MARINA CLEMENTE CONDE.

Ao Dr. HÉLIO TEDESCO SILVA JR, da Disciplina de Nefrologia da Escola Paulista de Medicina - Universidade Federal de São Paulo, pela oportunidade de trabalhar nesta instituição que sempre me acolheu muito bem.

Aos colegas da Turma 85, FABIO “CHUPS”, RACHEL, LÉO, JÚ, LUCAS, FABI, IVAN, EDU, PAULINHA, FABIÃO, GUS, GUIZÃO, VINÍCIUS, RAPHA e GUIGA. Obrigado pelo incentivo e compreensão durante esses dois anos.

Aos meus colegas de pós graduação, ADRIANE, CARLA, CÁSSIA, FÁBIO, GIOVANE, HSU, IVAN, PRISCILA, VALÉRIA e VERÔNICA, por todos os momentos bons e ruins que passamos juntos no mocó e no Pirajá. 
Às secretárias da Disciplina de Periodontia MÁRCIA MARIA DOS SANTOS e GILMARA LUÍSA HORTÊNCIO.

À equipe do Hospital do Rim e Hipertensão, Dra. MARIA LÚCIA S. VAZ, CARMEN R. PUJOL, LUCIANE C. DE SOUZA e SIDNEY PEDRO, pela atenção e ajuda na seleção dos sujeitos da pesquisa.

À CAROLINE GOMES PAIXÃO, aluna de graduação da FOUSP, pela colaboração no desenvolvimento deste trabalho.

Às bibliotecárias AGUIDA, GLÁUCI e VÂNIA, pela correção na formatação das referências bibliográficas.

À CAPES pela bolsa de Mestrado no programa Demanda Social.

À FUNDAÇÃO DE AMPARO À PESQUISA DO ESTADO DE SÃO PAULO, que auxiliou financeiramente e possibilitou a realização deste trabalho (FAPESP processo $n^{0}$ 04/13167-1). 
"Os dias prósperos não vêm por acaso; nascem de muita fadiga e persistência" 
Sekiguchi RT. Avaliação clínica do crescimento gengival induzido por ciclosporina-A e tacrolimus em indivíduos transplantados renais: estudo prospectivo [Dissertação de Mestrado]. São Paulo: Faculdade de Odontologia da Universidade de São Paulo; 2006.

\section{RESUMO}

Este estudo teve como objetivos avaliar a ocorrência de crescimento gengival derivado da administração de duas drogas imunossupressoras diclosporina-A (CsA) e tacrolimus, em indivíduos transplantados renais, e verificar as possíveis alterações dos parâmetros clínicos periodontais (IP, JEC-MG, PCS, NCI e SS) após o início da terapia imunossupressora. Foram avaliados dois grupos: grupo CsA que consistiu de 20 indivíduos que receberam o protocolo de imunossupressão composto por ciclosporina-A e o grupo tacrolimus que consistiu de 20 indivíduos que receberam tacrolimus. Ambos os grupos foram avaliados em três momentos: momento prétransplante, 30 dias após o transplante renal (momento 30 dias) e 90 dias após o transplante renal (momento 90 dias). Em todas as avaliações foram registrados os seguintes parâmetros clínicos: distância da junção esmalte-cemento à margem gengival (JEC-MG), profundidade clínica de sondagem (PCS), nível clínico de inserção (NCl), sangramento à sondagem (SS), índice de placa (IP) e índice de crescimento gengival (ICG). Foi observada redução significante do IP, em ambos os grupos, entre o momento pré-transplante e o momento 90 dias, mas não houve diferença significante entre os grupos nos três momentos avaliados. Com relação ao SS, foi observado no grupo tacrolimus uma redução significante entre o momento pré-transplante e o momento 30 dias $(p=0,001)$ e entre o momento pré-transplante e o momento 90 dias $(p<0,001)$. Também não houve diferença significante entre os grupos nos momentos avaliados. Não foi encontrada diferença significante entre os grupos com relação à JEC-MG e PCS nos três momentos. Quanto ao NCl, houve 
diferença significante entre $\propto$ momentos pré-transplante e 30 dias $(p=0,015)$, e entre os momentos pré-transplante e 90 dias $(p=0,03)$, independentemente do grupo. Com relação ao ICG, foi observado no grupo CsA diferença significante entre os momentos pré-transplante e 30 dias $(p<0,001)$, pré-transplante e 90 dias $(p<0,001)$ e entre 30 dias e 90 dias. No grupo tacrolimus, foi observada diferença significativa no ICG entre os momentos pré-transplante e 90 dias $(p=0,007)$ e entre 30 dias e 90 dias $(p=0,007)$. Ainda com relação ao ICG, o grupo ciclosporina-A sempre apresentou médias superiores ao grupo tacrolimus e essa diferença foi significativa nos momentos 30 dias $(p=0,03)$ e 90 dias $(p=0,014)$. Os autores concluíram que ambos os grupos apresentaram crescimento gengival após 90 dias de terapia imunossupressora. Entretanto, a média do índice de crescimento gengival do grupo CsA foi significantemente maior que a média do grupo tacrolimus após 30 dias e 90 dias. Além disso, os parâmetros clínicos periodontais IP, SS, JEC-MG, PCS e NCl não apresentaram diferenças significativas entre os grupos durante o estudo.

Palavras-Chave: Ciclosporina; Tacrolimo; Crescimento excessivo da gengiva; Doenças periodontais 
Sekiguchi RT. Avaliação do crescimento gengival induzido por ciclosporina-A e tacrolimus em indivíduos transplantados renais: estudo prospectivo [Dissertação de Mestrado]. São Paulo: Faculdade de Odontologia da Universidade de São Paulo; 2006.

\section{ABSTRACT}

The purpose of this study was to evaluate the occurrence of gingival overgrowth induced by cyclosporin-A (CyA) and tacrolimus, in kidney transplant patients, and to verify the possible changes of the periodontal parameters (plaque index, bleeding on probing, distance of the enamel-cement junction to gingival margin, probing depth and clinical attachment level) after the beginning of the immunosuppressant therapy. Two groups were evaluated: group CyA that consisted of 20 individuals who received CyA and the group tacrolimus that consisted of 20 individuals who received tacrolimus. Both groups were evaluated at three moments: pre-transplant moment, 30 days after the kidney transplant ( 30 days moment) and 90 days after the kidney transplant (90 days moment). In all these evaluations we registered the following parameters: plaque index (PI), bleeding on probing (SS), distance of enamel-cement junction to gingival margin (JEC-MG), probing depth (PD), clinical attachment level (CAL) and gingival overgrowth index (GO). It was observed a significant reduction of the $\mathrm{PI}$ in both groups, between the pre-transplant moment and the 90 days moment, but it was not observed any significant difference between the groups in the three evaluated moments. A significant reduction was found in the SS between the pretransplant moment and the 30 days moment $(p=0,001)$, and between the pretransplant moment and the 90 days moment $(p<0,001)$ for the group tacrolimus. Again it was not found any significant difference between the groups in the evaluated moments. It was not found any significant difference between the groups in the three moments of the study when the JEC-MG and PD were compared. About the CAL, it 
was found a significant difference between the pre-transplant moment and the 30 days moment, and between the pre-transplant moment and the 90 days moment, independently of the group compared. When we evaluated the GO in the CyA group we found a significant difference between the pre-transplant moment and 30 days moment $(p<0,001)$, the pre-transplant moment and the 90 days moment $(p<0,001)$ and between the 30 days moment and the 90 days moment. In the group tacrolimus, it was observed a significant difference in the GO between the pre-transplant moment and the 90 days moment $(p=0,007)$ and between the 30 days moment and the 90 days moment $(p=0,007)$. The group CyA always presented superior $G O$ mean scores when compared to the group tacrolimus and this difference was significant at the 30 days moment $(p=0,03)$ and 90 days moment $(p=0,014)$. The authors concluded that both groups presented gingival overgrowth after 90 days of immunosuppressant therapy. However, the mean GO scores of the group CyA was significantly higher than the mean of the group tacrolimus after 30 days and 90 days. Moreover, periodontal clinical parameters PI, SS, JEC-MG, PD and CAL did not present significant differences between the groups during the study.

Keywords: Cyclosporine; Tacrolimus; Gingival overgrowth; Periodontal diseases 


\section{LISTA DE ILUSTRAÇÕES}

Figura 4.1 - Esquema de estudo. 35

Figura 4.2 - Ilustração da avaliação do crescimento gengival com relação ao eixo vertical. 38

Figura 4.3 - llustração da avaliação do crescimento gengival com relação ao eixo horizontal. 


\section{LISTA DE TABELAS}

Tabela 4.1 - Monitoramento da concentração de tacrolimus conforme os períodos após o transplante renal. 33

Tabela 4.2 - Dosagem de corticosteróide conforme o período após o transplante renal. 34

Tabela 4.3 - Monitoramento pré-estabelecido da concentração sérica de ciclosporina-A, conforme os períodos após o transplante renal. 35

Tabela 5.1 - Dados demográficos dos sujeitos da pesquisa 41

Tabela 5.2 - Média, mediana, desvio padrão e comparação dos grupos experimentais com relação à JEC-MG (em milímetros) nos três momentos avaliados. 42

Tabela 5.3 - Média, mediana, desvio padrão e comparação dos grupos experimentais com relação à PCS (em milímetros) nos três momentos avaliados. 43 
Tabela 5.4 - Média, mediana, desvio padrão e comparação dos grupos experimentais com relação ao $\mathrm{NCl}$ (em milímetros) nos três momentos avaliados 44

Tabela 5.5 - Média, mediana, desvio padrão e comparação dos grupos com relação ao $\mathbb{P}$ nos três momentos avaliados. 45

Tabela 5.6 - Média, mediana, desvio padrão e comparação dos grupos com relação ao SS nos três momentos avaliados

Tabela 5.7 - Média, mediana, desvio padrão e comparação entre os grupos com relação ao índice de crescimento gengival adaptado de Seymour, Smith e Turnbull (1985) 48

Tabela 5.8 - Distribuição dos indivíduos de acordo com grupo e ocorrência de crescimento gengival clinicamente significante 50 


\section{LISTA DE ABREVIAÇÕES E SIGLAS}

$\begin{array}{ll}\text { APCD } & \text { Associação Paulista de Cirurgiões Dentistas } \\ \text { CsA } & \text { Ciclosporina-A } \\ \text { CAL } & \text { "Clinical attachment level" } \\ \text { FOUSP } & \text { Faculdade de Odontologia da Universidade de São Paulo } \\ \text { GO } & \text { "Gingival overgrowth index" } \\ \text { IG } & \text { Índice Gengival } \\ \text { IP } & \text { Índice de Placa bacteriana } \\ \text { JEC-MG } & \text { Distância da junção esmalte-cemento à margem gengival } \\ \text { mg } & \text { miligrama } \\ \text { mL } & \text { mililitro } \\ \text { mm } & \text { milímetro } \\ \text { NCI } & \text { Nível clínico de inserção } \\ \text { ng } & \text { nanograma } \\ \text { PCS } & \text { Profundidade clínica de sondagem } \\ \text { PI } & \text { "Plaque index" } \\ \text { PNIFESP } & \text { Universidade Federal de São Paulo } \\ & \end{array}$




\section{SUMÁRIO}

p.

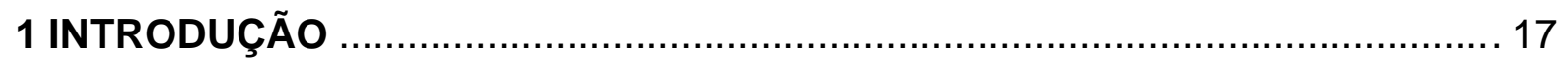

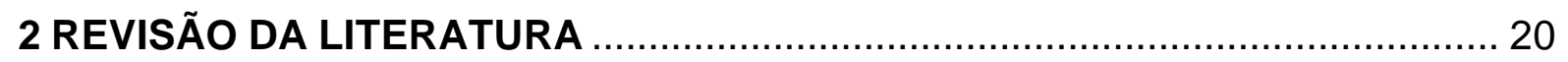

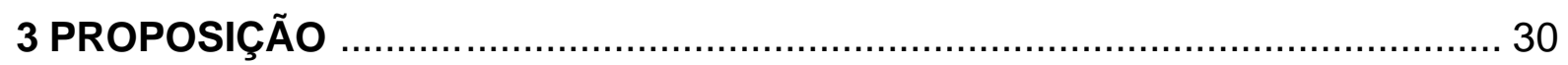

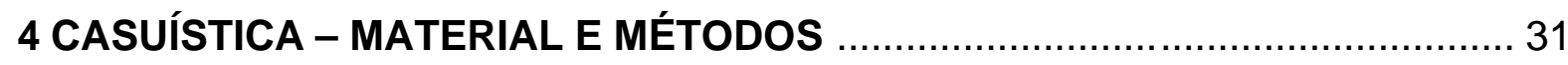

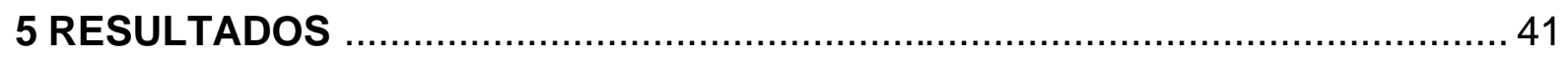

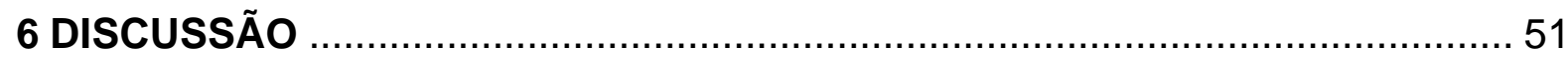

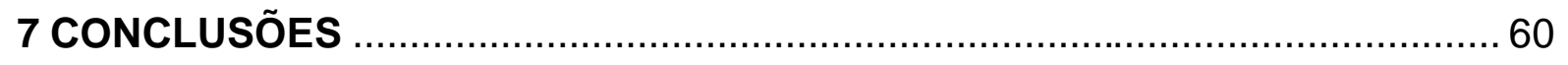

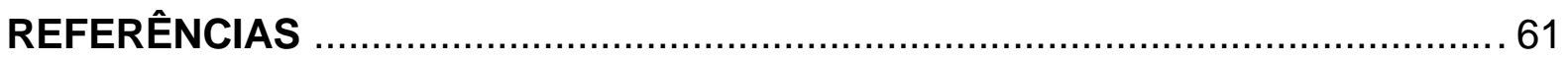

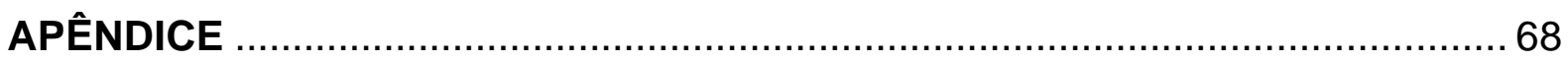

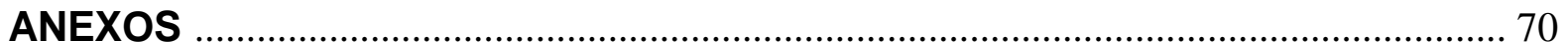




\section{INTRODUÇÃO}

O crescimento gengival induzido por drogas é caracterizado por um aumento no volume gengival, localizado geralmente nas papilas gengivais, sem se estender além da junção mucogengival (BADER; LEJEUNE; MESSNER, 1998). Este tipo de alteração gengival está freqüentemente associado a efeitos colaterais da administração sistêmica de drogas como fenitoína (ANGELOPOULUS, 1975), nifedipina (JONES, 1986) e ciclosporina-A (CsA) (CALNE et al., 1981; RATEITSCHAK-PLÜSS et al., 1983).

O crescimento gengival induzido pela CsA pode afetar todas as regiões da boca (TYLDESLEY; ROTTER, 1984), mas encontra-se mais evidente na região dos dentes anteriores (RATEITSCHAK-PLÜSS et al., 1983; SOMACARRERA et al., 1994). Algumas vezes, tal alteração pode se estender à coroa do dente e interferir na oclusão, mastigação e fonética do indivíduo, ou seja, em sua função bucal (FRISKOPP; KLINTMALM, 1986; JAMES et al., 2000). O envolvimento pode ser tão severo a ponto de causar problemas psicológicos para aqueles que apresentam esse efeito colateral (JAMES et al., 2000).

Vários estudos tentaram associar a etiologia do crescimento gengival em indivíduos transplantados que utilizam drogas imunossupressoras, com níveis de placa bacteriana (MCGAW; LAM; COATES, 1987; SEYMOUR; SMITH, 1991), presença de doença periodontal, dosagem e duração da terapia, concentração plasmática da droga (SEYMOUR; JACOBS, 1992) e suscetibilidade genética (DROZDZIK et al., 2005). Entretanto, a influência individual de cada um destes 
fatores ainda é desconhecida, assim como a exata patogênese do crescimento gengival (BOLTCHI; REES; IACOPINO, 1999; PERNU; PERNU; KNUUTTILA, 1993).

A CsA é um polipeptídeo cíclico produzido pelo fungo Tolypocladium inflatum Gams e utilizado como agente imunossupressor em pacientes com órgãos transplantados (BADER; LEJEUNE; MESSNER, 1998; HERNÁNDEZ et al., 2000). A ocorrência de efeitos indesejáveis da CsA no tecido gengival de humanos foi inicialmente observada por Rateitschak-Pluss et al. (1983). A prevalência de crescimento gengival em indivíduos imunossuprimidos que fazem uso de CsA varia entre 12,5\% a 84,6\% (PERNU et al., 1992; ROMITO et al., 2004; SARAIVA, 2000; SEYMOUR; SMITH; ROGERS, 1987; SOMACARRERA et al., 1994; THOMASON; SEYMOUR; RICE, 1993).

O tacrolimus, ou FK 506, é um macrolídeo descoberto em 1984, produzido pela fermentação da bactéria Streptomyces tsukubaensis (KINO et al., 1987). O tacrolimus tem sido utilizado como agente imunossupressor, representando uma alternativa à CsA, e empregado com sucesso na última década para prevenir a rejeição de transplantes renais, hepáticos e cardíacos (JAMES et al., 2000).

Alguns efeitos colaterais da CsA e do tacrolimus têm sido considerados semelhantes, incluindo nefrotoxicidade, neurotoxicidade e indução de um estado diabético (STARZL et al., 1990). Entretanto, os estudos que compararam o crescimento gengival relacionado ao uso da CsA e do tacrolimus para tratamento da rejeição de transplantes, têm apresentado resultados controversos em relação ao último. Alguns relatos de casos clínicos associaram a ocorrência deste efeito colateral com a utilização do acrolimus (ADAMS; FAMILI, 1991), ainda que com freqüência menor do que à atribuída para os que utilizaram CsA (ASANTE-KORANG et al., 1996). Todavia, a maior parte dos estudos que investigaram a efetividade do 
tacrolimus sugeriu que o mesmo não provoca crescimento gengival, favorecendo seu uso (ASANTE-KORANG et al., 1996; COX; FREESE, 1996; SHIELD; MCGRATH; GOSS, 1997).

Ellis et al. (2004) compararam a prevalência de crescimento gengival em indivíduos que recebiam CsA ou tacrolimus, e observaram que a prevalência e a severidade de crescimento gengival era menor em indivíduos que faziam uso de tacrolimus.

Recentemente, alguns estudos relataram a diminuição ou resolução do crescimento gengival pela substituição da CsA pelo tacrolimus em transplantados renais (ANGELOPOULUS, 1975; JAMES et al., 2000) e hepáticos (BADER; LEJEUNE; MESSNER, 1998).

Devido a esses resultados controversos encontrados na literatura e ao fato de que a grande maioria dos estudos serem transversais, o que dificulta o estabelecimento de uma relação causal direta, consideramos a realização de um estudo prospectivo para avaliar as possíveis alterações das características gengivais de indivíduos sob utilização de tacrolimus, visando um melhor conhecimento dos efeitos colaterais desta droga imunossupressora.

Este projeto faz parte de uma linha de pesquisa relacionada ao crescimento gengival induzido por CsA em indivíduos transplantados renais (GNOATTO, 2001; PUSTIGLIONI, 2001; SARAIVA, 2000, 2002) e cardíacos (ROMITO, 2000; ROMITO et al., 2004) da Disciplina de Periodontia do Departamento de Estomatologia da Faculdade de Odontologia da Universidade de São Paulo. 


\section{REVISÃO DA LITERATURA}

A ciclosporina-A (CsA), droga inicialmente desenvolvida como um agente antifúngico, teve suas propriedades imunossupressoras descobertas por Borel et al. (1977). Depois desta importante descoberta, a CsA passou a ser utilizada na prevenção de rejeição de transplantes e também no tratamento de doenças autoimunes. Segundo os autores, essa droga foi obtida por meio da fermentação de dois fungos (Trichoderma polysporum e Cylindrocarpon lucidu) e seu mecanismo de ação não é totalmente conhecido, mas há evidências que a CsA inibe a produção de anticorpos contra antígenos de células-T dependentes (BOREL et al., 1977; LAUPACIS et al., 1982).

De acordo com Daley e Wysocki (1984), a CsA exerce seu efeito imunossupressivo seletivo de três maneiras diferentes: 1) inibe a ativação dos macrófagos e assim interfere na síntese de interleucina-1;2) evita a produção de receptores de interleucina-1 nas superfícies das células T-helper e também a síntese de interleucina-2; e 3) evita a produção de receptores de interleucina-2 nas células-T indiferenciadas, bloqueando a produção de mais células T-helper, T-supressoras e T-killers. Além disso, um fato muito importante é que as doses suficientes para suprimir as funções das células-T pouco influenciam, ou não influenciam as funções das células-B, deixando o indivíduo parcialmente imunossuprimido.

Calne et al. (1981) realizaram o primeiro estudo utilizando a CsA com finalidade de evitar a rejeição de um transplante renal em humanos. A partir dos resultados deste estudo, muitos hospitais em todo o mundo passaram a utilizar a CsA para praticamente todos os tipos de transplante de órgãos. Com o crescente 
uso desse medicamento, foi também possível observar seus efeitos colaterais, como nefrotoxicidade, hepatoxicidade, tremores, hirsutismo, desenvolvimento de linfomas e crescimento gengival. Segundo os autores, não há como prever a severidade dos efeitos colaterais provocados pelo uso de CsA.

Tyldesley e Rotter (1984) notaram que o efeito colateral associado ao uso de CsA mais significante era a nefrotoxicidade, particularmente no transplantado renal. Outros efeitos diretos estavam de acordo com aqueles já descritos anteriormente.

Na Periodontia, um assunto que vem sendo estudado há algumas décadas é o crescimento gengival derivado do uso de CsA. Rateitschak-Plüss et al. (1983) foram os primeiros a relatar o crescimento gengival induzido pelo uso de ciclosporina-A.

Segundo alguns autores, o crescimento gengival poderia ocorrer tanto na região anterior quanto na posterior, mas na maioria dos casos a severidade era maior nas áreas interpapilares da região anterior, e com maior freqüência nas faces vestibulares (ADAMS; DAVIES, 1984; DALEY; WYSOCKI, 1984; RATEITSCHAKPLÜSS et al., 1983).

As análises histológicas dos tecidos gengivais que sofreram alteração mostraram que o crescimento gengival induzido pela CsA era indistinguível do crescimento resultante do uso de fenitoína (ROSTOCK; FRY; TURNER, 1986; WYSOCKI et al., 1983). As principais características desses tecidos foram descritas como um aumento no número de fibroblastos (MARIANI et al., 1996; WYSOCKI et al., 1983); presença de uma subpopulação de fibroblastos caracterizados por uma produção elevada de colágeno (RATEITSCHAK-PLÜSS et al., 1983; WYSOCKI et al., 1983); presença de tecido conjuntivo bastante vascularizado (MARIANI et al., 1996; RATEITSCHAK-PLÜSS et al., 1983; ROSTOCK; FRY; TURNER, 1986; 
WYSOCKI et al., 1983); presença de infiltrado inflamatório crônico (LAMBERTENGUI et al., 1986; ROSTOCK; FRY; TURNER, 1986); presença de epitélio com certo grau de hiperplasia (LAMBERTENGUI et al., 1986; MARIANI et al., 1996; PISANTY et al., 1990; ROSTOCK; FRY; TURNER, 1986); e presença abundante de substância fundamental amorfa no tecido conjuntivo (MARIANI et al., 1993; MARIANI et al., 1996).

A prevalência de crescimento gengival em indivíduos imunossuprimidos varia entre $12,5 \%$ a $84,6 \%$ (SOMACARRERA et al., 1994; PERNU et al., 1992; SARAIVA, 2000, 2002; ROMITO et al., 2004). A grande variação nos resultados dos estudos se deve às diferentes técnicas e aos métodos empregados para mensurar o crescimento gengival. Dentre os estudos que utilizaram uma metodologia semelhante ao nosso estudo, foi observado uma variação de $20 \%$ a $30 \%$ de crescimento gengival (SEYMOUR; SMITH; ROGERS, 1987; THOMASON; SEYMOUR; RICE, 1993).

Muitos autores tentaram relacionar o crescimento gengival derivado do uso de ciclosporina-A com a sua dosagem, duração da terapia imunossupressora, presença de irritantes locais como placa bacteriana e cálculo, idade do hospedeiro, mas até hoje nenhuma associação foi estabelecida.

Daley, Wysocki e Day (1986) estudaram a influência do tempo de uso de CsA, dose média diária, concentração plasmática média, qualidade de higiene oral, gênero e idade do indivíduo no momento em que a terapia havia iniciado, com a ocorrência e severidade do crescimento gengival. Participaram desse estudo 100 indivíduos que utilizaram CsA por pelo menos três meses, sendo que 53 apresentaram crescimento gengival grau leve a moderado e 17 apresentaram grau severo. Quando foi comparado o tempo de uso da droga e o crescimento, os autores 
observaram que as alterações foram maiores no intervalo de três a seis meses, atingindo um platô após 12 meses. Quanto à dose média diária e concentração plasmática média, eles notaram que todos os sujeitos que receberam doses maiores que $700 \mathrm{mg}$ por dia ou concentrações plasmáticas maiores que $155 \mathrm{ng} / \mathrm{mL}$ exibiram certo grau de crescimento gengival. Além disso, foi encontrado correlação entre a presença de placa bacteriana e a presença de crescimento gengival.

Wysocki et al. (1983) não encontraram correlação entre o nível sérico de CsA e a presença de crescimento gengival. Também sugeriram que o grau de crescimento gengival estaria, em parte, relacionado à presença de irritantes locais como a placa bacteriana, cálculo dental, restaurações inadequadas e ao efeito da respiração bucal. Além disso, concluíram que a sensibilidade individual a CsA poderia ser um fator predominante na ocorrência dessa alteração.

Lambertenghi et al. (1986) afirmaram que a presença de irritantes locais não pode ser considerada como a única causa para o aparecimento do crescimento da gengiva, pois essa condição também ocorre em indivíduos cuja higiene oral é adequada. Baseados nisso, eles concordaram com a hipótese de Wysocki et al. (1983) de que a sensibilidade individual a CsA seria a explicação mais aceitável.

McGaw, Lam e Coates (1987) tentaram correlacionar a incidência e severidade do crescimento gengival induzido pela CsA com o acúmulo de placa bacteriana, presença de gengivite e nível sérico e salivar de CsA. Trinta sujeitos participaram da pesquisa, sendo 15 homens e 15 mulheres. Oito sujeitos $(26,7 \%)$ foram classificados como responsivos ao crescimento gengival, que variou de uma ou mais papilas interdentais afetadas a extensas áreas com a gengiva chegando a recobrir grande parte da coroa dental. Os valores do índice de placa e presença de gengivite foram superiores no grupo responsivo ao crescimento quando comparados 
ao grupo não responsivo. Quanto ao nível de ciclosporina presente na saliva, o grupo responsivo apresentou valores superiores ao grupo não responsivo. Além disso, um fato curioso foi a observação da correlação positiva entre o nível de CsA salivar, o índice de placa e o índice de crescimento gengival. Essa correlação fez os autores sugerirem que a placa bacteriana poderia ser considerada um reservatório local de CsA.

Tyldesley e Rotter (1984) estudaram o crescimento gengival em 36 sujeitos transplantados renais, dentre eles 23 homens e 13 mulheres. Foi observado que nove indivíduos (25\%) que faziam uso de CsA apresentaram crescimento gengival. No grupo controle composto por transplantados renais tratados com outros imunossupressores, nenhum indivíduo apresentou crescimento. As áreas mais afetadas se apresentavam eritematosas e o controle da placa bacteriana nas mesmas era inadequado. Os autores sugeriram que o controle adequado de placa bacteriana seria uma excelente medida para controlar 0 aparecimento do crescimento gengival, entretanto, não sabiam se apenas esse procedimento seria suficiente para eliminar tal acometimento.

Ross et al. (1989) investigaram os efeitos da ciclosporina-A em 21 crianças que realizaram transplantes hepáticos. Os autores também concluíram que a placa bacteriana poderia representar um papel na iniciação ou alteração no desenvolvimento do crescimento gengival.

Devido a grande controvérsia envolvendo a etiologia do crescimento gengival induzido pela ciclosporina-A, Seymour e Smith (1991) investigaram a eficácia do controle de placa bacteriana com finalidade de prevenir o crescimento gengival. Participaram deste estudo 27 indivíduos que foram divididos em dois grupos, um grupo recebeu orientação de higiene bucal e o outro não. Seis meses após o início 
do estudo, os autores observaram que ambos os grupos apresentaram crescimento gengival estatisticamente significante. Foi concluído que a atenção com o acúmulo de placa bacteriana e a remoção de irritantes locais gera benefícios para a saúde gengival, mas essas medidas apenas não são capazes de prevenir o crescimento da gengiva. Tais autores sugeriram que a patogênese do aumento gengival induzido por CsA é multifatorial.

A partir desses resultados, muitos estudos passaram a objetivar a resolução do aumento gengival. Daly (1992) apresentou um relato de caso de um indivíduo que apresentava alteração gengival devido ao uso de CsA e não obteve bons resultados após controle de placa bacteriana e raspagem radicular. A resolução do aumento gengival só foi possível após a redução da dosagem diária da droga. Seus achados aumentaram a possibilidade de que a redução da dosagem de CsA a um nível crítico poderia levar à resolução do crescimento gengival.

Atualmente, um novo imunossupressor conhecido como FK 506 ou tacrolimus vem sendo bastante estudado na área da Periodontia, principalmente devido aos resultados de estudos clínicos que não mostraram associação dessa nova droga com a presença de alteração nos tecidos gengivais.

O tacrolimus é um antibiótico macrolídeo descoberto em 1984 por um laboratório de Tsukuba, no Japão, e se mostrou um imunossupressor bastante eficiente. Essa droga é produzida pela fermentação da bactéria Streptomyces tsukubaensis e é capaz de suprimir as respostas imunológicas humoral e celular, representando uma alternativa à ciclosporina-A. Estudos in vitro demonstraram que o tacrolimus foi capaz de imunossuprimir um sistema com a concentração 100 vezes menor que a ciclosporina-A. Já os estudos in vivo demonstraram que sua capacidade é 10 vezes maior que a CsA (GOTO et al., 1991). 
Este agente imunossupressor tem sido empregado com sucesso na última década para prevenir rejeição de órgãos em transplantados renal, hepático e cardíaco, e demonstrou eficácia comprovada como terapia primária e terapia de resgate em transplantes renais e hepáticos (JAMES et al., 2001).

Starzl et al. (1990) utilizaram o tacrolimus, ainda em fase experimental, em 36 indivíduos transplantados renais. Os indivíduos foram acompanhados por quatro a treze meses e os autores observaram que o tacrolimus provocou efeitos adversos semelhantes aos da CsA, mas em menor severidade. Esses resultados estão de acordo com Uemoto et al. (1993) que acompanharam por um a nove meses o uso combinado de tacrolimus com esteróides em 22 crianças que receberam transplantes hepáticos.

Os prós e contras do uso de tacrolimus em transplantados hepáticos foram discutidos por Cox e Freese (1996) que relataram que o tacrolimus foi superior à CsA na prevenção da rejeição de órgãos. Os autores observaram que a absorção do tacrolimus é independente da bile, de forma que os níveis sanguíneos terapêuticos são rapidamente alcançados levando a permanência mais curta e custo reduzido nos hospitais. Entretanto, altas doses dessa droga podem causar efeitos adversos neurológicos, desordens linfoproliferativas e cardiomiopatias hipertróficas em crianças. Estes efeitos são semelhantes aos da ciclosporina-A quando utilizadas em baixas doses. Ainda segundo os autores, o tacrolimus não causa hirsutismo.

Os estudos que observaram os efeitos colaterais do tacrolimus na cavidade bucal apresentaram resultados controversos. Em sua grande maioria esses estudos não relataram qualquer tipo de alteração nos tecidos gengivais. Asante-Korang et al. (1996) avaliaram por um período médio de 29 meses, 29 crianças transplantadas cardíacas que fizeram uso de tacrolimus e não observaram alteração gengival. Da 
mesma maneira, Armitage et al. (1993) observaram o impacto do uso do tacrolimus em 26 crianças que receberam transplantes cardíacos e também não notaram crescimento gengival.

Um estudo importante foi realizado por James et al. (2001) que avaliaram prospectivamente indivíduos transplantados renais que receberam tacrolimus, desde a cirurgia de transplante, e foram acompanhados por 18 meses. Os autores realizaram exames dentários e moldagens intrabucais que originaram modelos de gesso para determinação do crescimento gengival. Nenhum dos indivíduos apresentou crescimento gengival clinicamente significativo, concluindo-se que o tacrolimus não apresentava efeitos adversos nos tecidos gengivais, sendo uma potencial alternativa para indivíduos susceptíveis ao desenvolvimento de crescimento gengival induzido por CsA.

Outros estudos, no entanto, associaram a ocorrência de alterações no volume gengival após a utilização do tacrolimus, ainda que com freqüência menor do que à atribuída ao uso de CsA. Shapiro et al. (1994) compararam aspectos clínicos da administração de tacrolimus e CsA em 48 crianças que receberam transplantes renais. Os autores observaram que o grupo que recebeu tacrolimus apresentou menor crescimento gengival comparado ao grupo da CsA. Resultados muito parecidos foram obtidos por Mayer et al. (1997) que acompanharam 303 indivíduos que utilizaram Tacrolimus e 145 que utilizaram CsA por 12 meses, na prevenção a rejeição de transplantes renais. Segundo os autores, menores incidências de crescimento gengival foram encontradas no grupo que recebeu tacrolimus.

Os resultados de Oettinger-Barak et al. (2001) também estão de acordo com os anteriores. Eles avaliaram 24 indivíduos transplantados hepáticos que utilizaram CsA ou tacrolimus e relataram que embora tenha ocorrido aumento gengival em 
ambos os grupos, no grupo que recebeu tacrolimus a incidência de crescimento gengival foi significativamente menor.

Shield, McGrath e Goss (1997) avaliaram a qualidade de vida em pacientes transplantados renais que fizeram uso de Tacrolimus ou CsA durante 12 meses. Os dados foram analisados em itens que incluíam, entre outros, a aparência física, no qual o Tacrolimus foi favorecido devido à menor incidência de crescimento gengival.

Chu et al. (2000) acompanharam 47 indivíduos que faziam uso de CsA e 10 que utilizavam tacrolimus para evitar rejeição de órgãos transplantados. Foram realizados modelos de gesso para avaliação do crescimento gengival, que resultou em $45,2 \%$ de incidência no grupo da CsA e 25,1\% no grupo do tacrolimus. Após um ano de tratamento periodontal não cirúrgico, o índice de crescimento gengival no grupo da CsA reduziu para 15,2\%. Os autores concluíram que o tratamento periodontal não cirúrgico foi efetivo na redução do crescimento gengival em ambos os grupos e recomendaram o controle da saúde bucal independentemente do protocolo imunossupressor utilizado.

Ellis et al. (2004) avaliaram em um estudo transversal o crescimento gengival em indivíduos transplantados renais que faziam uso de CsA e tacrolimus. Seus resultados mostraram que a prevalência e a severidade do crescimento gengival induzido por tacrolimus em indivíduos transplantados adultos são menores quando comparados aos indivíduos que fizeram uso de CsA.

Recentemente, alguns estudos relataram a diminuição ou resolução do crescimento gengival pela substituição da CsA pelo tacrolimus em transplantados renais e hepáticos. Budde et al. (1996), substituíram a CsA pelo tacrolimus em 25 indivíduos receptores de transplantes renais, devido a sinais de rejeição do novo órgão. Após conversão da medicação e acompanhamento por aproximadamente 
oito meses, houve diminuição do crescimento gengival. Da mesma forma, Bader, Lejeune e Messner (1998) relataram um caso de substituição de CsA por tacrolimus em um indivíduo transplantado hepático em que exaltaram o uso do tacrolimus devido ao maior conforto que esta droga promoveu e também pela grande redução do crescimento gengival.

Busque et al. (1999) substituíram a CsA por FK 506 em 13 indivíduos transplantados renais aproximadamente 35 meses após o transplante, devido à ocorrência de crescimento gengival. Os pacientes foram acompanhados por 12 meses. Após três meses da conversão de medicamento, 5 indivíduos tiveram redução completa do crescimento gengival. No décimo segundo mês, todos os indivíduos tiveram resolução do crescimento gengival.

Assim como os estudos acima, James et al. (2000), Thorp et al. (2000) e Hernandez et al. (2000) avaliaram prospectivamente indivíduos transplantados que apresentavam crescimento gengival induzido pela CsA e tiveram a medicação substituída para tacrolimus. Todos os indivíduos apresentaram redução significativa do crescimento gengival durante os períodos estudados.

Devido aos resultados controversos encontrados na literatura e ao fato de a grande maioria dos estudos serem transversais, consideramos a realização de um estudo prospectivo para avaliar as possíveis alterações das características gengivais de indivíduos sob utilização de CsA e tacrolimus, visando um melhor conhecimento dos efeitos colaterais destas drogas imunossupressoras. 


\section{PROPOSIÇÃO}

Este estudo teve como objetivos:

3.1 Avaliar e comparar a ocorrência de crescimento gengival associado à administração das drogas imunossupressoras ciclosporina-A (CsA) e tacrolimus em indivíduos transplantados renais, em três momentos: pré-transplante, 30 dias e 90 após o transplante renal;

3.2 Verificar as possíveis alterações dos índices e parâmetros clínicos periodontais (Índice de placa bacteriana, sangramento à sondagem, distância da junção esmaltecemento à margem gengival, profundidade clínica de sondagem e nível clínico de inserção) com relação aos grupos do estudo e com relação ao tempo de terapia imunossupressora. 


\section{CASUÍSTICA - MATERIAL E MÉTODOS}

\subsection{Casuística}

Este estudo foi submetido e aprovado pela Comissão de Ética em Pesquisa da Faculdade de Odontologia - Universidade de São Paulo e pela Comissão de Ética em Pesquisa do Hospital do Rim e Hipertensão - UNIFESP (Universidade Federal de São Paulo) (Anexo A e B).

Solicitou-se aos pacientes que lessem o termo de consentimento livre esclarecido que descrevia resumidamente o estudo. Após o completo entendimento de seu conteúdo, foi solicitada a assinatura do mesmo (Apêndice A).

Foram avaliados 67 indivíduos candidatos a transplante renal. Desses, 12 desistiram de participar do estudo após a avaliação inicial, outros 10 tiveram de ser excluídos do estudo por uso de nifedipina após receberem o transplante. Dois sujeitos tiveram sua medicação imunossupressora alterada durante o período de três meses e também foram excluídos. Outros três indivíduos desistiram de participar após a segunda avaliação por motivos desconhecidos.

Participaram de todas as avaliações clínicas deste estudo 40 indivíduos que realizavam tratamento ro Ambulatório da Disciplina de Nefrologia da Unidade de Transplantes Renais do Hospital do Rim e Hipertensão - Escola Paulista de Medicina - Universidade Federal de São Paulo (UNIFESP). Esses indivíduos foram submetidos ao transplante renal devido a distúrbios renais variados e receberam, 
após a cirurgia, dois protocolos de imunossupressão diferentes que serão descritos a seguir.

Ambos os grupos foram avaliados em três momentos: antes do transplante renal (momento pré-transplante), 30 dias após o transplante (momento 30 dias) e 90 dias após transplante (momento 90 dias).

\subsection{Protocolos de imunossupressão}

Os protocolos de imunossupressão utilizados após o transplante renal foram instituídos e monitorados pela equipe médica do Hospital do Rim e Hipertensão da UNIFESP. O Grupo CsA consistiu de 20 indivíduos que receberam o protocolo tríplice de imunossupressão com ciclosporina-A, azatioprina e um corticosteróide, e o Grupo tacrolimus consistiu de 20 indivíduos que receberam um protocolo tríplice de imunossupressão com tacrolimus, azatioprina e um corticosteróide.

O modelo de protocolo imunossupressor utilizado pelo Hospital do Rim e Hipertensão, seguido durante o estudo está descrito a seguir.

4.2.1 protocolo de imunossupressão com tacrolimus (FK 506)

Administração de cápsulas de $1 \mathrm{mg}$ e de $5 \mathrm{mg}$ de tacrolimus por via oral, uma hora antes ou duas horas após as refeições. A dose diária inicial foi de 0,3 mg/kg 
divididas em duas tomadas diárias $(0,15 \mathrm{mg} / \mathrm{kg}$ a cada 12 horas). A dose de tacrolimus foi calculada com base no peso atual do paciente e foi ajustada de acordo com as concentrações de tacrolimus do sangue total determinadas pelo método de ensaio comercial clinicamente validado (ELISA ou com micropartículas enzimáticas $\left(m_{x}\right)$. Os ajustes da dose de tacrolimus também foram realizados baseados na sua tolerabilidade e na presença de eventos adversos.

\section{Monitoramento de nível sérico de tacrolimus}

As amostras de sangue foram coletadas 10 a 12 horas depois de administrada a dose oral noturna (determinações do nível residual). Todas as amostras foram coletadas em tubos contendo EDTA, etiquetados com a identificação do paciente, data e hora em que a amostra de sangue foi coletada. A dose de tacrolimus poderia ser aumentada ou diminuída para atingir as seguintes concentrações no sangue total, na ausência de toxicidade inaceitável ou rejeição, conforme a Tabela 4.1.

Tabela 4.1 - Monitoramento pré-estabelecido da concentração de tacrolimus conforme os períodos após o transplante renal

\begin{tabular}{l|l}
\hline Período após o transplante & Concentração de tacrolimus \\
\hline 0 a 15 dias & 15 a $20 \mathrm{ng} / \mathrm{mL}$ \\
16 a 30 dias & 10 a $15 \mathrm{ng} / \mathrm{mL}$ \\
31 a 90 dias & 8 a $15 \mathrm{ng} / \mathrm{mL}$ \\
Após 90 dias & 5 a $15 \mathrm{ng} / \mathrm{mL}$ \\
\hline
\end{tabular}




\section{Dosagem de azatioprina}

Ambos os grupos fizeram uso de Azatioprina, sendo que sua dosagem inicial foi de $2 \mathrm{mg} / \mathrm{kg} / \mathrm{dia}$. Esta dosagem foi reduzida em casos de suspeita de toxicidade.

\section{Dosagem de corticosteróide}

Ambos os grupos do estudo receberam corticosteróide (metilprednisolona e prednisona) conforme discriminado na Tabela 4.2.

\begin{tabular}{|c|c|}
\hline Período após o transplante & Dosagem do corticosteróide \\
\hline Mesmo dia do transplante & $1 \mathrm{~g} / \mathrm{kg} /$ dia de metilprednisolona \\
\hline 2 a 28 dias & 0,4 a $0,5 \mathrm{mg} / \mathrm{kg} /$ dia de prednisona \\
\hline 29 a 45 dias & 0,3 a $0,4 \mathrm{mg} / \mathrm{kg} / \mathrm{dia}$ de prednisona \\
\hline 46 a 90 dias & 0,2 a $0,3 \mathrm{mg} / \mathrm{kg} / \mathrm{dia}$ de prednisona \\
\hline 91 a 180 dias & 0,15 a $0,2 \mathrm{mg} / \mathrm{kg} / \mathrm{dia}$ de prednisona \\
\hline 180 a 360 dias & 0,10 a $0,15 \mathrm{mg} / \mathrm{kg} /$ dia de prednisona \\
\hline
\end{tabular}

4.2.2 protocolo de imunossupressão com ciclosporina-A

A dosagem inicial de 8 a $10 \mathrm{mg} / \mathrm{kg} / \mathrm{dia}$ foi seguida de ajustes e 0 monitoramento pré-estabelecido da concentração de ciclosporina-A foi conforme segue a Tabela 4.3 . 
Tabela 4.3 - Monitoramento pré-estabelecido da concentração sérica de ciclosporina-A, conforme os períodos após o transplante renal

\begin{tabular}{l|l}
\hline Período após o transplante & Concentração sérica de ciclosporina-A \\
\hline 1 a 30 dias & 200 a $400 \mathrm{ng} / \mathrm{mL}$ \\
31 a 90 dias & 150 a $300 \mathrm{ng} / \mathrm{mL}$ \\
91 a 360 dias & 100 a $200 \mathrm{ng} / \mathrm{mL}$ \\
\hline
\end{tabular}

\subsection{Método}

Os sujeitos da pesquisa seguiram o seguinte esquema de estudo, resumido abaixo:

\section{PRÉ-TRANSPLANTE}

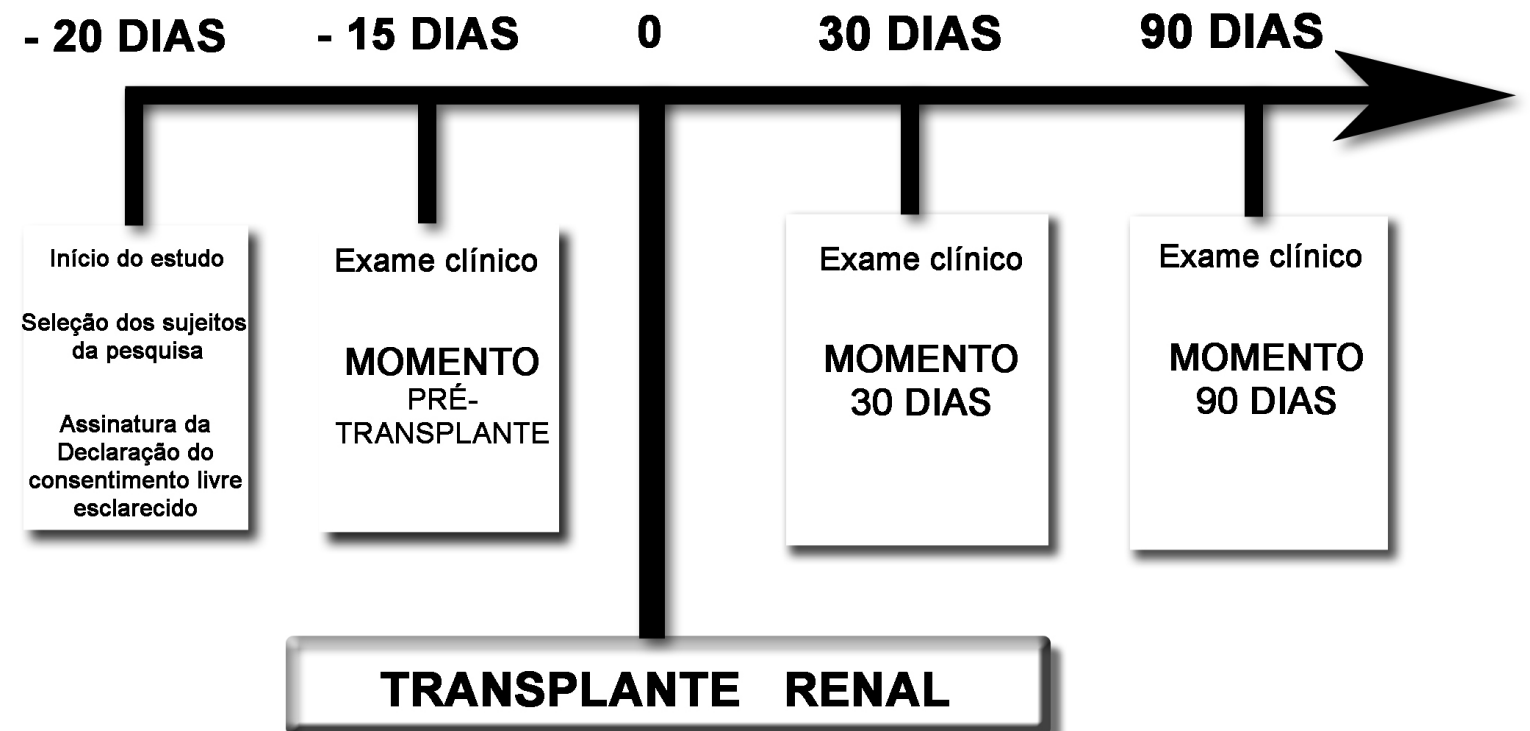

Figura 4.1 - Esquema de estudo 


\subsection{1 anamnese}

Os indivíduos responderam às perguntas presentes na ficha de anamnese utilizada pela Disciplina de Periodontia da FOUSP (Anexo C). Nesta ficha também constava a data prevista do transplante e os medicamentos que os indivíduos faziam uso.

4.3.2 critérios de inclusão e exclusão

\section{Critérios de inclusão}

Foram incluídos no estudo indivíduos com idade acima de 18 anos, de ambos os sexos e que apresentassem no mínimo seis dos oito dentes anteriores de cada arcada, sem sinais clínicos e radiográficos de periodontite.

Além disso, foi considerado como período de espera máximo entre a avaliação do momento pré-transplante e a realização do transplante, o período de 15 dias. Os indivíduos que ultrapassaram esse período foram reavaliados previamente à cirurgia de transplante renal para que estivessem dentro do período de 15 dias.

\section{Critérios de exclusão}

Foram excluídos do estudo todos os indivíduos fumantes e/ou diabéticos, e que no momento pré-transplante apresentassem algum tipo de crescimento 
gengival. Aqueles que utilizavam as seguintes drogas: nifedipina, diltiazen, verapamil, fenitoína, valproato de sódio e azitromicina também foram excluídos do estudo.

Cabe salientar que os indivíduos diagnosticados como portadores de doença periodontal, durante o estudo, foram encaminhados para tratamento na disciplina de Periodontia da Faculdade de Odontologia da Universidade de São Paulo.

\subsection{3 exame clínico}

Nos exames clínicos foram examinados apenas os seis dentes posicionados de maneira mais anterior da arcada superior e inferior. O exame clínico foi realizado por um único examinador treinado e calibrado. Os parâmetros clínicos foram medidos em seis sítios diferentes dos dentes (disto-vestibular, centro-vestibular, mésio-vestibular, disto-lingual, centro-lingual e mésio-lingual), com uma sonda periodontal manual milimetrada (Hu-Friedy - PCPUNC $\left.n^{\circ} 15\right)$ e registrados nas fichas utilizadas pela Disciplina de Periodontia da Faculdade de Odontologia da Universidade de São Paulo. (Anexo D)

Os parâmetros clínicos periodontais registrados foram:

1. Distância da junção esmalte-cemento à margem gengival (JEC-MG): medida que vai da linha esmalte-cemento à margem gengival.

2. Profundidade clínica de sondagem (PCS): distância compreendida entre a margem gengival e o fundo do sulco gengival ou da bolsa periodontal. 
3. Nível clínico de inserção (NCl): distância compreendida entre a junção esmalte-cemento e o fundo do sulco gengival ou da bolsa periodontal.

Os índices registrados foram:

1. Índice de placa bacteriana (IP): registrado de acordo com Silness e Löe (1964).

2. Índice de sangramento à sondagem (SS): realizado após a medida da profundidade clínica de sondagem e registrado de forma dicotômica nos seis sítios de cada dente.

3. Índice de crescimento gengival adaptado de Seymour, Smith e Turnbull (1985) (ICG): registrado nas papilas vestibulares, palatinas e linguais dos dentes de cada indivíduo. Cada papila recebeu um escore que variava entre 0 e 5, dependendo do grau de crescimento tanto no eixo horizontal quanto no vertical. Assim, um total de 20 papilas (10 superiores e 10 inferiores) foram examinadas em cada indivíduo, e o escore máximo que cada indivíduo poderia alcançar era de 100. Por isso, o valor encontrado em cada indivíduo foi expresso em percentagem.

As Figuras 4.2 e 4.3 ilustram como as papilas foram avaliadas com relação ao eixo vertical e horizontal, respectivamente.

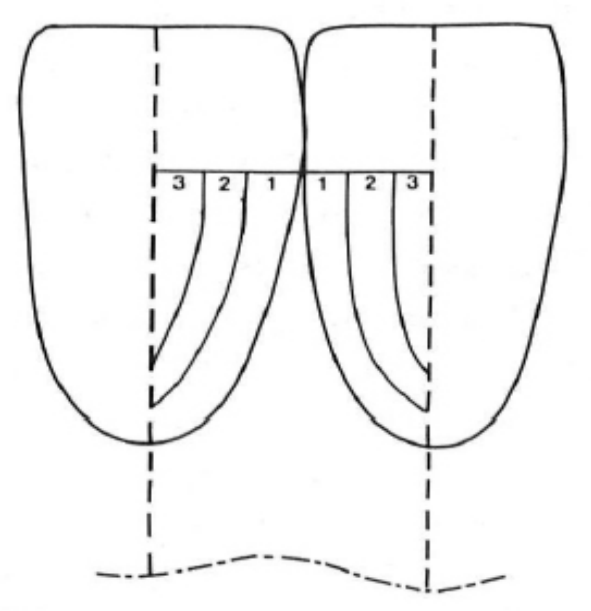

Figura 4.2 - Ilustração da avaliação do crescimento gengival com relação ao eixo vertical (SEYMOUR; SMITH; TURNBULL, 1985) 


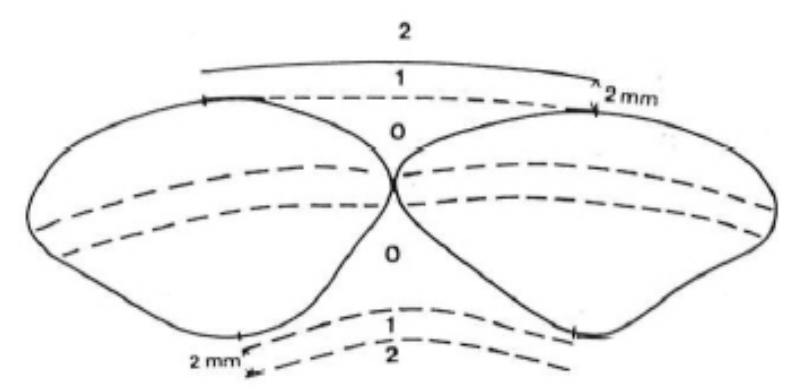

Figura 4.3 - llustração da avaliação do crescimento gengival com relação ao eixo horizontal (SEYMOUR; SMITH; TURNBULL, 1985)

Utilizando os escores do índice adaptado de Seymour, Smith e Turnbull (1985), classificamos os indivíduos que apresentaram um valor acima ou igual a $30 \%$ como portadores de crescimento gengival clinicamente significante, ou seja, portadores de crescimento gengival onde uma possível intervenção cirúrgica seria necessária para sua correção (SEYMOUR; JACOBS, 1992; THOMASON; SEYMOUR e RICE, 1993).

Os mesmos procedimentos de exame clínico foram realizados nos momentos 30 dias e 90 dias após a realização do transplante renal.

Cabe ressaltar que, em todas as avaliações clínicas, os indivíduos receberam orientação de higiene bucal e profilaxia por meio de taças de borracha e pedra pomes. 


\subsection{Método estatístico}

Inicialmente foram calculadas as médias das variáveis idade, JEC-MG, PCS, NCI, IP e SS por indivíduo. O índice adaptado de Seymour, Smith e Turnbull (1985) foi apresentado como percentagem.

Os grupos CsA e tacrolimus foram comparados com relação às médias de idade e com relação às médias de JEC-MG, PCS, NCI, IP, SS e ICG nos momentos pré-transplante, 30 dias e 90 dias após o transplante renal. A aderência à curva normal foi verificada pelo teste de Kolmogorov-Smirnov, e a homogeneidade das variâncias foi testada pelo teste de Levene. O teste ANOVA para medidas repetidas foi utilizado para comparar as médias dos grupos ao longo do tempo. O teste de Tukey foi usado para detectar entre quais grupos existiam as diferenças.

Nos casos em que a distribuição não era normal ou as variâncias não eram homogêneas, foram utilizados os testes não paramétricos de Mann-Whitney para comparação das médias dos dois grupos em cada intervalo de tempo, e o teste de Friedman para verificar alterações ao longo do tempo em cada grupo.

O teste de qui-quadrado foi utilizado para verificar se existia associação entre grupo e índice de crescimento gengival, nos três momentos do estudo.

Todos os testes foram realizados utilizando-se um nível $\alpha$ de $5 \%$ para rejeição da hipótese de nulidade. 


\section{RESULTADOS}

\subsection{Amostra analisada}

Participaram do estudo 40 indivíduos com idade entre 21 a 60 anos (média de 39,3 anos e desvio padrão de 11,7 anos). Na Tabela 5.1 encontra-se a distribuição dos dados demográficos dos sujeitos da pesquisa.

Tabela 5.1 - Dados demográficos dos sujeitos da pesquisa

\begin{tabular}{lcccc}
\hline & N (\%) & Média \pm DP & Min-max & p \\
\hline Idade & & & & 0,98 \\
Ciclosporina & $20(100 \%)$ & $39,3 \pm 11,7$ & $22-57$ & (teste t) \\
Tacrolimus & $20(100 \%)$ & $39,4 \pm 12,9$ & $21-60$ & \\
\hline Gênero & & & & 0,74 \\
CsA & & & (qui- \\
Masculino & $08(40,0 \%)$ & & quadrado) \\
Feminino & $12(60,0 \%)$ & & \\
Tacrolimus & & & \\
Masculino & $11(55,0 \%)$ & & \\
Feminino & $9(45,0 \%)$ & & \\
\hline
\end{tabular}

A Tabela 5.1 mostra que os dois grupos foram homogêneos com relação à idade $(p=0,98)$ e gênero $(p=0,74)$. 


\subsection{Avaliação dos parâmetros clínicos}

5.2.1 distância da junção esmalte-cemento à margem gengival (JEC-MG)

Na Tabela 5.2 encontra-se a comparação dos grupos experimentais com relação à JEC-MG, nos três momentos avaliados (pré-transplante, 30 dias e 90 dias)

Tabela 5.2 - Média, mediana, desvio padrão e comparação dos grupos experimentais com relação à JEC-MG (em milímetros), nos três momentos avaliados

\begin{tabular}{|c|c|c|c|c|}
\hline Momentos & & CsA & Tacrolimus & $\stackrel{\stackrel{p}{(M a n n-W h i t n e y)}}{\text { (Mand }}$ \\
\hline Pré-transplante & $\begin{array}{c}\mathbf{N} \\
\text { Média } \\
\text { Mediana } \\
\text { DP' }^{\dagger}\end{array}$ & $\begin{array}{c}20 \\
0,36 \\
0,13 \\
0,51\end{array}$ & $\begin{array}{c}20 \\
0,19 \\
0,06 \\
0,32\end{array}$ & 0,36 \\
\hline 30 dias & $\begin{array}{c}\mathbf{N} \\
\text { Média } \\
\text { Mediana } \\
\mathrm{DP}^{\dagger}\end{array}$ & $\begin{array}{c}20 \\
0,26 \\
0,06 \\
0,52\end{array}$ & $\begin{array}{c}20 \\
0,19 \\
0,06 \\
0,34\end{array}$ & 0,84 \\
\hline 90 dias & $\begin{array}{c}\mathbf{N} \\
\text { Média } \\
\text { Mediana } \\
\text { DP }^{\dagger}\end{array}$ & $\begin{array}{c}20 \\
0,13 \\
0,00 \\
0,89\end{array}$ & $\begin{array}{c}20 \\
0,13 \\
0,02 \\
0,34\end{array}$ & 0,73 \\
\hline $\begin{array}{c}\mathbf{p} \\
\text { (Friedman) }\end{array}$ & & $0,009^{*}$ & 0,10 & \\
\hline
\end{tabular}

${ }^{\dagger} \mathrm{DP}=$ desvio padrão; * $=$ estatisticamente significativo

Foi observado que não houve diferença significativa entre as médias dos dois grupos no momento pré-tranplante $(p=0,36)$, momento 30 dias $(p=0,84)$ e momento 90 dias $(p=0,73)$. 
No grupo tacrolimus não houve diferença significativa entre as médias dos diferentes tempos experimentais. No grupo CsA foi observada alteração significativa ao longo do tempo $(p=0,009)$. De acordo com o teste de comparações múltiplas Student-Newman-Keuls, no grupo ciclosporina houve diferença significativa entre o momento pré-tranplante e o momento 90 dias $(p=0,026)$.

5.2.2 profundidade clínica de sondagem (PCS)

Na Tabela 5.3 observa-se a comparação dos grupos experimentais com relação à profundidade clínica de sondagem, nos três momentos avaliados.

Tabela 5.3 - Média, mediana, desvio padrão e comparação dos grupos experimentais com relação à PCS (em milímetros), nos três momentos avaliados

\begin{tabular}{|c|c|c|c|c|}
\hline Momentos & & CsA & Tacrolimus & $\begin{array}{c}\text { p } \\
\text { (Mann- } \\
\text { Whitney) }\end{array}$ \\
\hline Pré-transplante & $\begin{array}{c}\mathbf{N} \\
\text { Média } \\
\text { Mediana } \\
\text { DP }^{\dagger}\end{array}$ & $\begin{array}{c}20 \\
1,87 \\
1,84 \\
0,26\end{array}$ & $\begin{array}{c}20 \\
1,83 \\
1,78 \\
0,44\end{array}$ & 0,62 \\
\hline 30 dias & $\begin{array}{c}\mathbf{N} \\
\text { Média } \\
\text { Mediana } \\
\mathbf{D P}^{\dagger}\end{array}$ & $\begin{array}{c}20 \\
1,87 \\
1,78 \\
0,33\end{array}$ & $\begin{array}{c}20 \\
1,78 \\
1,75 \\
0,39\end{array}$ & 0,58 \\
\hline 90 dias & $\begin{array}{c}\mathbf{N} \\
\text { Média } \\
\text { Mediana } \\
\mathbf{D P}^{\dagger}\end{array}$ & $\begin{array}{c}20 \\
2,05 \\
1,86 \\
0,89\end{array}$ & $\begin{array}{c}20 \\
1,85 \\
1,84 \\
0,35\end{array}$ & 0,62 \\
\hline $\begin{array}{c}p \\
\text { (Friedman) }\end{array}$ & & 0,10 & 0,09 & \\
\hline
\end{tabular}

${ }^{\dagger} \mathrm{DP}=$ desvio padrão 
Não houve diferença significativa entre as médias dos dois grupos no momento pré-transplante $(p=0,62)$, no momento 30 dias $(p=0,58)$ e no momento 90 dias $(p=0,62)$. Não houve alteração significativa ao longo do tempo no grupo CsA $(p=0,10)$ e também no grupo tacrolimus $(p=0,09)$.

5.2.3 nível clínico de inserção (NCl)

$\mathrm{Na}$ Tabela 5.4 encontra-se a comparação dos grupos experimentais com relação ao nível clínico de inserção, nos três momentos avaliados.

Tabela 5.4 - Média, mediana, desvio padrão e comparação dos grupos experimentais com relação ao $\mathrm{NCl}$ (em milímetros), nos três momentos avaliados

\begin{tabular}{|c|c|c|c|}
\hline Momentos & & CsA & Tacrolimus \\
\hline Pré-transplante & $\begin{array}{c}\mathbf{N} \\
\text { Média } \\
\text { Mediana } \\
\mathrm{DP}^{\dagger}\end{array}$ & $\begin{array}{c}20 \\
2,23 \\
2,02 \\
0,63\end{array}$ & $\begin{array}{c}20 \\
2,02 \\
1,98 \\
0,60\end{array}$ \\
\hline 30 dias & $\begin{array}{c}\mathbf{N} \\
\text { Média } \\
\text { Mediana } \\
\text { DPt }^{\dagger}\end{array}$ & $\begin{array}{c}20 \\
2,13 \\
2,00 \\
0,54\end{array}$ & $\begin{array}{c}20 \\
1,98 \\
1,97 \\
0,46\end{array}$ \\
\hline 90 dias & $\begin{array}{c}\mathbf{N} \\
\text { Média } \\
\text { Mediana } \\
\text { DP }^{\dagger}\end{array}$ & $\begin{array}{c}20 \\
2,14 \\
2,00 \\
0,54\end{array}$ & $\begin{array}{c}20 \\
1,98 \\
1,94 \\
0,45\end{array}$ \\
\hline $\begin{array}{r}\text { ANOVA: efeito gr } \\
\text { efeito ter } \\
\text { efeito int }\end{array}$ & $\begin{array}{l}=0,30 ; \\
=0,01^{*} \\
\text { grupo } \times \text { te }\end{array}$ & & \\
\hline
\end{tabular}


Apenas o efeito tempo foi significativo $(p=0,01)$. De acordo com o teste de Tukey, houve diferença significativa entre os momentos pré-transplante e 30 dias $(p=0,015)$, e pré-tranplante e 90 dias $(p=0,03)$, independentemente do grupo.

5.2.4 índice de placa bacteriana (IP)

A Tabela 5.5 mostra a comparação dos grupos do estudo com relação ao Índice de placa bacteriana, nos três momentos do estudo.

Tabela 5.5 - Média, mediana, desvio padrão e comparação dos grupos com relação ao IP, nos três momentos avaliados

\begin{tabular}{|c|c|c|c|c|}
\hline Momentos & & CsA & Tacrolimus & $\begin{array}{c}p \\
\text { (Mann- } \\
\text { Whitney) }\end{array}$ \\
\hline Pré-transplante & $\begin{array}{c}\mathbf{N} \\
\text { Média } \\
\text { Mediana } \\
\text { DP }^{\dagger}\end{array}$ & $\begin{array}{l}20 \\
1,2 \\
1,3 \\
0,6\end{array}$ & $\begin{array}{l}20 \\
1,3 \\
1,0 \\
0,7\end{array}$ & 0,94 \\
\hline 30 dias & $\begin{array}{c}\mathbf{N} \\
\text { Média } \\
\text { Mediana } \\
\text { DP }^{\dagger}\end{array}$ & $\begin{array}{l}20 \\
0,9 \\
0,8 \\
0,5\end{array}$ & $\begin{array}{l}20 \\
1,0 \\
0,8 \\
0,4\end{array}$ & 0,12 \\
\hline 90 dias & $\begin{array}{c}\mathbf{N} \\
\text { Média } \\
\text { Mediana } \\
\text { DP }^{\dagger}\end{array}$ & $\begin{array}{l}20 \\
0,9 \\
0,8 \\
0,5\end{array}$ & $\begin{array}{l}20 \\
0,9 \\
0,8 \\
0,2\end{array}$ & 0,69 \\
\hline $\begin{array}{c}p \\
\text { (Friedman) }\end{array}$ & & $0,001^{*}$ & $0,005^{\star}$ & \\
\hline
\end{tabular}

${ }^{\dagger} \mathrm{DP}=$ desvio padrão; * diferença significativa a $5 \%$ 
Houve uma redução significativa no IP no grupo $\operatorname{CsA}(p=0,001)$ e no grupo tacrolimus $(p=0,005)$. De acordo com o teste de comparações múltiplas StudentNewman-Keuls, no grupo CsA houve diferença significativa entre o momento prétransplante e o momento 30 dias $(p=0,005)$ e entre o momento pré-transplante e 0 momento 90 dias $(p=0,005)$. No grupo tacrolimus houve diferença significativa entre o momento pré-transplante e o momento 30 dias $(p=0,004)$ e entre o momento prétransplante e o momento 90 dias $(p=0,0003)$. No entanto, não houve diferença significativa entre os grupos em qualquer momento do estudo.

\subsubsection{Sangramento à sondagem}

$\mathrm{Na}$ Tabela 5.6 encontra-se a comparação dos grupos experimentais com relação ao sangramento a sondagem. 
Tabela 5.6 - Média, mediana, desvio padrão e comparação dos grupos com relação ao SS nos três momentos avaliados

\begin{tabular}{|c|c|c|c|}
\hline Momentos & & CsA & Tacrolimus \\
\hline \multirow{4}{*}{ Pré-transplante } & $\mathbf{N}$ & 20 & 20 \\
\hline & Média & $30,5 \%$ & $35,2 \%$ \\
\hline & Mediana & $31,5 \%$ & $31,5 \%$ \\
\hline & $\mathrm{DP}^{\dagger}$ & $12,7 \%$ & $22,8 \%$ \\
\hline \multirow{4}{*}{30 dias } & $\mathbf{N}$ & 20 & 20 \\
\hline & Média & $28,1 \%$ & $27,3 \%$ \\
\hline & Mediana & $21,5 \%$ & $22,0 \%$ \\
\hline & $\mathrm{DP}^{\dagger}$ & $15,3 \%$ & $16,6 \%$ \\
\hline \multirow{4}{*}{90 dias } & $\mathbf{N}$ & 20 & 20 \\
\hline & Média & $26,3 \%$ & $23,5 \%$ \\
\hline & Mediana & $21,5 \%$ & $20,5 \%$ \\
\hline & $\mathbf{D P}^{\dagger}$ & $14,7 \%$ & $10,9 \%$ \\
\hline \multicolumn{4}{|c|}{$\begin{array}{l}\text { ANOVA: efeito grupo: } p=0,93 \\
\text { efeito tempo: } p<0,001^{*}\end{array}$} \\
\hline
\end{tabular}

Houve alteração significativa ao longo do tempo $(p<0,001)$, e a interação grupo-tempo foi significativa $(p=0,03)$.

De acordo com o teste de Tukey, houve diferença significativa no grupo tacrolimus entre as médias do momento pré-transplante e o momento 30 dias $(p=0,001)$ e entre o momento pré-transplante e o momento 90 dias $(p<0,001)$. 
5.2.6 índice de crescimento gengival (ICG)

Na Tabela 5.7 encontra-se a comparação dos grupos com relação ao índice de crescimento gengival adaptado de Seymour, Smith e Turnbull (1985).

Tabela 5.7 - Média, mediana, desvio padrão e comparação entre os grupos com relação ao índice de crescimento gengival adaptado de Seymour, Smith e Turnbull (1985)

\begin{tabular}{|c|c|c|c|c|}
\hline Momentos & & CsA & Tacrolimus & $\begin{array}{c}\mathbf{p} \\
\text { (Mann-Whitney) }\end{array}$ \\
\hline Pré-transplante & $\begin{array}{c}\mathbf{N} \\
\text { Média } \\
\text { Mediana } \\
\text { DP }^{\dagger}\end{array}$ & $\begin{array}{l}20 \\
0,0 \\
0,0 \\
0,0\end{array}$ & $\begin{array}{l}20 \\
0,0 \\
0,0 \\
0,0\end{array}$ & 1,00 \\
\hline 30 dias & $\begin{array}{c}\mathbf{N} \\
\text { Média } \\
\text { Mediana } \\
\text { DP }^{\dagger}\end{array}$ & $\begin{array}{c}20 \\
8,9 \% \\
0,0 \\
14,9 \%\end{array}$ & $\begin{array}{l}20 \\
0,0 \\
0,0 \\
0,0\end{array}$ & $0,03^{*}$ \\
\hline 90 dias & $\begin{array}{c}\mathbf{N} \\
\text { Média } \\
\text { Mediana } \\
\text { DP }^{\dagger}\end{array}$ & $\begin{array}{c}20 \\
17,9 \% \\
15,0 \% \\
18,8 \% \\
\end{array}$ & $\begin{array}{c}20 \\
6,4 \% \\
0,0 \\
11,9 \%\end{array}$ & $0,014^{*}$ \\
\hline $\begin{array}{c}p \\
\text { (Friedman) }\end{array}$ & & $<0,001^{*}$ & $0,007^{*}$ & \\
\hline
\end{tabular}

${ }^{\dagger} \mathrm{DP}=$ desvio padrão; * diferença significativa a 5\%

Os grupos foram comparados com relação ao índice de crescimento gengival adaptado de Seymour, Smith e Turnbull (1985). Verificou-se um aumento significativo no ICG no grupo CsA ( $p<0,001)$ e no grupo tacrolimus $(p=0,007)$.

De acordo com o teste de comparações múltiplas Student-Newman-Keuls, no grupo CsA houve diferença significativa entre o momento pré-transplante e o 
momento 30 dias $(p=0,006)$, entre $\circ$ momento pré-transplante e o momento 90 dias $(p<0,001)$, e entre o momento 30 dias e o momento 90 dias $(p=0,0002)$. No grupo tacrolimus houve diferença significativa entre o momento pré-transplante e 0 momento 90 dias $(p=0,049)$.

A média do ICG foi significativamente maior no grupo CsA que no grupo tacrolimus após 30 dias $(p=0,03)$ e após 90 dias $(p=0,014)$.

5.2.7 ocorrência do crescimento gengival clinicamente significante

A Tabela 5.8 mostra a distribuição dos indivíduos que apresentaram ou não crescimento gengival clinicamente significante, durante o período avaliado. 
Tabela 5.8 - Distribuição dos indivíduos de acordo com grupo e a ocorrência de crescimento gengival clinicamente significante

\begin{tabular}{|c|c|c|c|c|c|c|c|}
\hline & & \multicolumn{6}{|c|}{ Momento pré-transplante } \\
\hline & & \multicolumn{3}{|c|}{ Crescimento gengival } & \multirow{3}{*}{\multicolumn{2}{|c|}{ Total }} & \multirow{3}{*}{$p$} \\
\hline & & \multicolumn{2}{|c|}{ Não } & Sim & & & \\
\hline & & $\mathrm{N}$ & $\%$ & $\mathrm{~N} \%$ & & & \\
\hline \multirow{6}{*}{ Grupos } & $\mathrm{CsA}$ & 20 & $100 \%$ & - & 20 & $100 \%$ & \multirow[b]{3}{*}{ - } \\
\hline & Tacrolimus & 20 & $100 \%$ & - & 20 & $100 \%$ & \\
\hline & Total & 40 & $100 \%$ & - & 40 & $100 \%$ & \\
\hline & & \multicolumn{5}{|c|}{ Momento 30 dias } & \\
\hline & & \multicolumn{2}{|c|}{ Não } & Sim & \multirow{2}{*}{\multicolumn{2}{|c|}{ Total }} & \multirow{2}{*}{$\begin{array}{c}\mathrm{p} \\
\text { (Fisher) }\end{array}$} \\
\hline & & $\mathrm{N}$ & $\%$ & $\mathrm{~N} \%$ & & & \\
\hline \multirow{6}{*}{ Grupos } & CsA & 18 & $90 \%$ & $0210 \%$ & 20 & $100 \%$ & \multirow{3}{*}{0,48} \\
\hline & Tacrolimus & 20 & $100 \%$ & - & 20 & $100 \%$ & \\
\hline & \multirow[t]{4}{*}{ Total } & 32 & $80 \%$ & $08 \quad 20 \%$ & 40 & $100 \%$ & \\
\hline & & \multicolumn{6}{|c|}{ Momento 90 dias } \\
\hline & & \multicolumn{2}{|c|}{ Não } & Sim & \multirow{2}{*}{\multicolumn{2}{|c|}{ Total }} & \multirow{2}{*}{$\begin{array}{c}\mathrm{p} \\
\text { (Fisher) }\end{array}$} \\
\hline & & $\mathrm{N}$ & $\%$ & $\mathrm{~N} \%$ & & & \\
\hline \multirow{3}{*}{ Grupos } & CsA & 16 & $80 \%$ & $20 \%$ & 20 & $100 \%$ & \multirow{3}{*}{0,66} \\
\hline & Tacrolimus & 18 & $90 \%$ & $10 \%$ & 20 & $100 \%$ & \\
\hline & Total & 20 & $50 \%$ & $50 \%$ & 40 & $100 \%$ & \\
\hline
\end{tabular}

Antes do transplante renal, nenhum indivíduo do grupo CsA ou tacrolimus apresentava crescimento gengival clinicamente significante. Trinta dias após o transplante, dois pacientes que receberam CsA já apresentavam crescimento gengival clinicamente significante, e nenhum paciente que recebia tacrolimus mostrou tal alteração. Não houve associação significativa entre crescimento gengival clinicamente significante e grupo $(p=0,48)$ no momento 30 dias.

Noventa dias após o transplante, quatro indivíduos do grupo CsA e dois do grupo tacrolimus apresentaram crescimento gengival clinicamente significante. Também não houve associação significativa entre crescimento gengival clinicamente significante e grupo nesse momento $(p=0,66)$. 


\section{DISCUSSÃO}

$\mathrm{Na}$ literatura, encontramos poucos estudos prospectivos que compararam a ocorrência de crescimento gengival decorrente do uso de CsA e tacrolimus. Uma possível explicação seria o fato de o tacrolimus ser um agente imunossupressor relativamente novo e seus estudos ainda estarem sendo realizados. De qualquer modo, a falta de estudos prospectivos foi levada em consideração para a realização deste trabalho, que faz parte de uma linha de pesquisa da disciplina de Periodontia da Faculdade de Odontologia da Universidade de São Paulo.

Um questionamento observado inicialmente foi com relação à nomenclatura encontrada na literatura para descrever a patologia que pode ocorrer nos tecidos gengivais após o tratamento com CsA e tacrolimus. Muitos autores utilizaram o termo hiperplasia gengival, no entanto, esse termo se refere a um aumento absoluto no volume de tecido gengival resultante do aumento da quantidade de um tipo celular, que nem sempre foi observado nos estudos que realizaram análise histológica do tecido gengival. Segundo Mariani et al. (1993), o termo mais apropriado seria crescimento gengival, pois vários estudos mostraram que o aumento de volume seria resultado do aumento da quantidade de elementos colagênicos da matriz do tecido conjuntivo, e do acúmulo de substância fundamental amorfa (TYLDESLEY; ROTTER, 1984; WYSOCKI et al., 1983). Em nosso estudo, como não sabemos a exata origem dessa alteração gengival, denominamos tal alteração como crescimento gengival.

Os indivíduos que participaram deste estudo eram inicialmente portadores de insuficiência renal terminal e realizavam sessões de hemodiálise três vezes por 
semana. Durante as sessões de hemodiálise, esses indivíduos poderiam apresentar diminuição no número de plaquetas, diminuição do fator III, tempo de sangramento prolongado e ainda fazer uso de anticoagulantes. Esses fatores poderiam aumentar o risco de hemorragia por parte desses pacientes e devido a isso, realizamos as avaliações clínicas do estudo no dia seguinte à sessão de hemodiálise, conforme a recomendação de DeRossi e Glick (1996).

Como pôde ser notado, os sujeitos desta pesquisa necessitavam de muitos cuidados especiais e, talvez por isso, a principal dificuldade foi estimulá-los a permanecerem participando do estudo. Muitos desses indivíduos residiam em cidades distantes do Hospital do Rim e Hipertensão - UNIFESP e não apresentavam condições financeiras de comparecerem às avaliações clínicas do estudo. Outros desistiam de participar do estudo por receio de se perderem no caminho entre o Hospital do Rim e Hipertensão e a clínica onde eram realizados os exames clínicos odontológicos. Conforme descrito nos resultados, inicialmente havia 67 indivíduos que aceitaram participar do estudo, porém apenas 40 sujeitos passaram pelas três avaliações e completaram o período total de avaliação do estudo.

Além desses fatores, uma outra dificuldade encontrada neste estudo foi a seleção dos sujeitos da pesquisa. No momento em que era realizada a primeira avaliação clínica (momento pré-transplante), a equipe médica não havia determinado qual terapia imunossupressora o indivíduo faria uso após a cirurgia de transplante renal. Assim, alguns indivíduos que estavam participando do estudo tiveram de ser excluídos depois de serem informados que utilizariam drogas que faziam parte dos critérios de exclusão.

Dentre as drogas que faziam parte dos critérios de exclusão, podemos citar os anticonvulsivantes (fenitoína, valproato de sódio) e os bloqueadores de canais de 
cálcio (nifedipina, diltiazen, verapamil). Tais drogas estão associadas ao desenvolvimento de crescimento gengival (ELLIS et al., 1999; KING et al., 1993; THOMASON et al., 1997) e fizeram parte dos critérios de exclusão do estudo para evitar suas influências nas possíveis alterações dos tecidos gengivais.

Os protocolos imunossupressores utilizados pelos indivíduos, que receberam o transplante de rim, foram determinados e prescritos pela equipe médica do Hospital do Rim e Hipertensão - UNIFESP. Tais protocolos apresentavam um esquema tríplice (utilização de três agentes imunossupressores) compostos por azatioprina, corticosteróide (metilprednisolona e prednisona) e o agente principal que poderia ser a CsA ou o tacrolimus. Segundo os estudos de Seymour, Smith e Rogers (1987) tanto a azatioprina quanto o corticosteróide não estão associados à ocorrência de crescimento gengival.

O exame clínico foi realizado apenas nos seis dos oito dentes mais anteriores da arcada superior e inferior. Não foram examinados os demais dentes, pois segundo vários autores (KANTARCI et al., 1999; MONTEBUGNOLI; BERNARDI; MAGELLI, 1996; SEYMOUR; SMITH, 1991; SEYMOUR; SMITH; ROGERS, 1987; THOMASON; SEYMOUR; RICE, 1993) quando avaliamos indivíduos que fazem uso de imunossupressores, a região anterior é a mais afetada, servindo como base para a avaliação dos demais parâmetros clínicos.

Com relação à média de idade dos indivíduos avaliados, os resultados encontrados estão bastante próximos da média de idade relatada em outros estudos (THOMASON; SEYMOUR; RICE, 1993; SOMACARRERA et al., 1994). A correlação entre o crescimento gengival e a idade dos indivíduos não está bem esclarecida na literatura. Segundo Daley, Wysocki e Day (1986), crianças e adolescentes, com idade de até 20 anos, apresentavam maior risco de desenvolver crescimento 
gengival. Isto poderia ser resultado da ação dos hormônios de crescimento nos fibroblastos. Os hormônios sexuais não pareciam ter influência, pois não houve diferença entre os gêneros na amostra estudada. Uma outra hipótese levantada pelos autores para explicar o maior risco em crianças e adolescentes foi a idade dos fibroblastos e suas capacidades de se dividir e secretar produtos. Essas hipóteses contrastam com os resultados obtidos por Seymour e Smith (1991), que sugeriram que quanto maior a idade dos indivíduos, maior seria sua predisposição a desenvolver crescimento gengival. Em nosso estudo, a média de idade dos indivíduos que apresentaram crescimento gengival clinicamente significante foi de 42,7 para o grupo CsA e 40 para o grupo tacrolimus, estando mais próximo dos resultados de Seymour e Smith (1991).

Uma grande discussão existente ainda hoje é com relação ao papel da placa bacteriana na etiologia do crescimento gengival. Daley, Wysocki e Day (1986) afirmaram que a presença da placa bacteriana estava associada com o aumento gengival, porém pouco podia ser dito sobre a relação entre quantidade de placa e severidade do aumento gengival. McGaw, Lam e Coates (1987) sugeriram que a placa bacteriana poderia ser um reservatório local de CsA, liberando a droga lentamente por meio de estímulos da saliva. Os autores ainda observaram que os indivíduos que apresentavam crescimento gengival também apresentavam maior grau de índice de placa bacteriana.

Em nosso estudo, observamos a evolução do índice de placa bacteriana com relação ao tempo. O Índice de placa bacteriana (SILNESS; LÖE, 1964) apresentou reduções intragrupos significativas quando foram comparados os momentos prétransplante e 30 dias, e pré-transplante e 90 dias, nos dois grupos (CsA e tacrolimus). No entanto, não houve diferença significativa entre os grupos em 
qualquer momento do estudo. Apesar da redução do índice de placa bacteriana, foi observada a ocorrência de crescimento gengival em ambos os grupos. Nossa opinião sobre a influência da placa bacteriana no desenvolvimento do crescimento gengival é de que a mesma não é um fator principal no desencadeamento de tal alteração. Algumas observações clínicas que chamaram nossa atenção foram as ocorrências de crescimento gengival em indivíduos com ótimo controle de placa e o inverso também.

Segundo Seymour e Smith (1991), um controle de placa adequado não inibe o desenvolvimento de crescimento gengival induzido por CsA. Ainda assim, os autores também afirmaram que apesar de não evitar o crescimento gengival, o controle adequado de placa e a remoção dos irritantes locais só trazem benefícios para a saúde gengival dos indivíduos transplantados renais.

Com relação ao registro de sangramento à sondagem (SS), observamos redução significativa no SS apenas no grupo tacrolimus quando foram comparados os momentos pré-transplante e 30 dias $(p=0,001)$ e pré-transplante e 90 dias $(p<0,001)$. Tais resultados estão de acordo com o estudo de Somacarrera et al. (1994).

A redução do SS possivelmente estaria associada com o adequado controle de placa bacteriana que foi intensamente orientado durante todo o estudo. É importante esclarecer que todos os sujeitos da pesquisa receberam orientações de higiene bucal e profilaxia com taça de borracha e pedra pomes durante as três avaliações. Uma outra hipótese para tal redução no SS seria o fato de os indivíduos terem iniciado após o transplante, o uso de antimicrobianos e antiinflamatórios (metilprednisolona e prednisona). Tais medicamentos poderiam inibir a proliferação bacteriana e também o quadro inflamatório. Alguns estudos determinaram que 
houve menos inflamação gengival em indivíduos tratados com agentes imunossupressores comparado com indivíduos não medicados (SCHULLER; FREEDMAN; LEWIS, 1973; KARDACHI; NEWCOMB, 1978).

A explicação mais provável de ter ocorrido redução significativa de SS apenas no grupo tacrolimus é que neste grupo houve menor ocorrência de crescimento gengival e conseqüentemente houve maior facilidade de controle adequado da placa bacteriana quando comparado ao grupo CsA.

Neste estudo, todos os sujeitos da pesquisa foram representados com um único valor médio para JEC-MG, PCS, NCI. Os valores médios e os desvios-padrão foram submetidos à análise estatística.

Quanto ao parâmetro clínico JEC-MG, ambos os grupos apresentaram redução após os 90 dias, mas essa redução foi significativa apenas no grupo CsA, entre o momento pré-transplante e o momento 90 dias $(p=0,026)$. Não foi observada diferença significante entre os grupos durante todo o estudo. Tal redução foi significativa apenas no grupo CsA devido, provavelmente, à diferença de ocorrência de crescimento gengival entre os grupos. A redução no parâmetro JEC-MG reflete o crescimento gengival no eixo vertical, confirmando que o grupo CsA apresentou crescimento gengival no eixo vertical maior que o grupo tacrolimus após 90 dias do estudo.

Com relação ao parâmetro clínico PCS, não houve diferença estatisticamente significante intragrupos e entre os grupos que receberam CsA e tacrolimus, durante todo o estudo. Esse resultado está de acordo com o estudo de Oettinger-Barak et al. (2001) que não demonstrou diferenças significantes entre o grupo que recebeu CsA e o grupo que recebeu tacrolimus. Segundo os autores, a terapia imunossupressora não teve influência alguma nos parâmetros periodontais acima citados. 
Quanto ao $\mathrm{NCl}$, foi observada redução significante apenas entre os momentos pré-transplante e 30 dias, e os momentos pré-transplante e 90 dias, independentemente do grupo comparado. Essa redução também pode ser explicada pelo uso de antimicrobianos e antiinflamatórios, e claro, pelo controle adequado de placa bacteriana.

A avaliação do crescimento gengival foi realizada por meio do índice adaptado de Seymour, Smith e Turnbull (1985) que teve como objetivo quantificar o crescimento gengival, resultando em um valor na forma de percentagem de áreas que apresentaram crescimento gengival.

Originalmente, o índice de Seymour, Smith e Turnbull (1985) foi descrito para ser realizado em modelos de gesso, entretanto, devido a dificuldades técnicas fizemos uma adaptação e realizamos as avaliações clinicamente. Também foi utilizado uma classificação dicotômica para classificar os indivíduos que apresentassem crescimento gengival clinicamente significante. Este termo, segundo Thomason, Seymour e Rice (1993) deve ser utilizado aos sujeitos que apresentarem valores de crescimento gengival de Seymour, Smith e Turnbull (1985) igual ou superior a 30 , ou seja, sujeitos que muito possivelmente necessitaria de cirurgia para correção gengival.

Uma das grandes dificuldades em estudar o crescimento gengival é comparar os resultados de estudos realizados por diferentes autores. Como não existe um padrão bem definido para mensurar o crescimento gengival cada autor escolhe o que achar mais adequado, dificultando a comparação dos resultados. $O$ índice de Seymour, Smith e Turnbull (1985) constitui uma mensuração bidimensional, levando em conta o crescimento em altura e em espessura. Por essas razões, ele foi escolhido para ser utilizado neste estudo. 
Utilizando o índice adaptado de Seymour, Smith e Turnbull (1985), observamos que após 30 dias o grupo CsA apresentou cinco (25\%) indivíduos que apresentaram certo grau de crescimento gengival, sendo que a média do ICG deste grupo foi de 8,9\%. Após 90 dias, quinze indivíduos do grupo CsA apresentaram crescimento gengival e a média do ICG desse grupo passou para 17,9\%. No grupo que recebeu tacrolimus, o aparecimento de crescimento gengival se deu somente após 90 dias e em cinco (25\%) indivíduos, sendo que a média de ICG do grupo foi de 6,4\%. Observamos que o índice médio foi significativamente maior no grupo CsA do que no grupo tacrolimus após 30 dias $(p=0,03)$ e 90 dias $(p=0,014)$. Esses resultados estão de acordo com os estudos de Bader, Lejeune e Messner (1998), James et al. (2000), e Oettinger-Barak et al. (2001).

Comparando nossos resultados com o estudo de Ellis et al. (2004), consideramos que os resultados de ambos os estudos foram bastante parecidos. Ellis et al. (2004) observaram para o grupo CsA a média de ICG de 22,4\% e para o grupo tacrolimus a média de $14,1 \%$.

Apesar disso, os valores médios do ICG que encontramos estão abaixo dos resultados do estudo de Thomason, Seymour e Rice (1993) que obteve ICG de 20,6\% para o grupo CsA. Uma possível explicação para tais resultados é que em nosso estudo, todos estavam sob a terapia imunossupressora tríplice, que utilizava além do agente imunossupressor principal (Csa ou tacrolimus), a azatioprina e um corticosteróide (metilprednisolona e prednisona). Segundo Thomason, Seymour e Ellis (2005), o uso de azatioprina e do corticosteróide faz com que a dosagem de CsA ou tacrolimus possa ser reduzida e isso possivelmente resultaria numa menor ocorrência de crescimento gengival. 
Considerando o crescimento gengival clinicamente significante descrito por Thomason, Seymour e Rice (1993), foi observado que no momento 30 dias apenas dois indivíduos (10\%) do grupo CsA e nenhum do grupo tacrolimus apresentaram tal alteração gengival. Após 90 dias, quatro indivíduos (20\%) do grupo CsA e dois (10\%) do grupo tacrolimus apresentaram crescimento gengival clinicamente significante. Não foi encontrada diferença significante entre os grupos CsA e tacrolimus em ambos os momentos com relação a essa análise de crescimento gengival.

Comparando esses resultados com o do estudo de Ellis et al. (2004), observamos que no estudo citado também não houve diferença significante entre os grupos CsA e tacrolimus $(p=0,053)$, apesar de os autores considerarem como diferença marginalmente significante. A diferença de metodologia entre o estudo atual e o realizado por Ellis et al. (2004) pode ser uma explicação para as diferenças nos resultados. O estudo de Ellis et al. (2004) é um estudo transversal e a média do tempo de uso dos imunossupressores foi de 31 meses para o grupo tacrolimus e 42 meses para o grupo CsA. Já nosso estudo, além de ser prospectivo, teve apenas três meses de tempo de uso dos imunossupressores.

Segundo alguns autores (DALEY; WYSOCKI; DAY, 1986; SOMACARRERA et al., 1994), nos primeiros 90 dias é possível observar os sinais clínicos evidentes de crescimento gengival, mas tal alteração se estabiliza apenas após 12 meses de duração da terapia imunossupressora. Em outras palavras, apesar de não observar diferença estatisticamente significante quando comparamos os grupos CsA e tacrolimus com relação à presença de crescimento gengival clinicamente significante após 90 dias, existe certa expectativa baseada na literatura, que após 12 meses 
ainda poderá ocorrer desenvolvimento do crescimento gengival nos outros indivíduos e a diferença entre os grupos CsA e tacrolimus será significante.

Por esta razão, é importante salientar que este estudo é parte de um projeto que pretende acompanhar os mesmos sujeitos da pesquisa por um período de até 360 dias. Durante esse período, seria possível aumentar o número de sujeitos da pesquisa e coletar um número de dados maior para a confirmação dos resultados apresentados nesse estudo de 90 dias. 


\section{CONCLUSÕES}

Os resultados obtidos, frente à metodologia empregada neste trabalho, fundamentam as seguintes conclusões:

7.1 Os indivíduos de ambos os grupos CsA e tacrolimus apresentaram crescimento gengival significativo após 90 dias de terapia imunossupressora, entretanto, a média do índice de crescimento gengival do grupo CsA foi significantemente maior que a média do grupo tacrolimus.

7.2 As médias dbs parâmetros clínicos periodontais IP, SS, JEC-MG e NCl de ambos os grupos sofreram reduções após os 90 dias do estudo. Com relação à comparação entre os grupos, não houve diferença significativa entre as médias dos parâmetros IP, SS, JEC-MG, PCS e NCl de ambos os grupos, em todos os momentos do estudo. 


\section{REFERÊNCIAS ${ }^{1}$}

Adams CK, Famili P. A study of the effects of the drug FK 506 on gingival tissues. Transplant Proc 1991;23(6):3193-4.

Adams D, Davies G. Gingival hyperplasia associated with cyclosporin A. A report of two cases. Br Dent J 1984;157:89.

Angelopoulos AP. Diphenylhydantoin gingival hyperplasia. A clinicopathological review. 1. Incidence, clinical features and histopathology. J Can Dent Assoc 1975;41(2):103-6.

Armitage JM, Fricker FJ, del Nido P, Starzl TE, Hardesty RL, Griffith BP. A decade (1982 to 1992) of pediatric cardiac transplantation and the impact of FK 506 immunosuppression. J Thorac Cardiovasc Surg 1993;105(3):464-72; discussion 4723.

Asante-Korang A, Boyle GJ, Webber SA, Miller SA, Fricker FJ. Experience of FK506 immune suppression in pediatric heart transplantation: a study of long-term adverse effects. J Heart Lung Transplant 1996;15(4):415-22.

Bader G, Lejeune S, Messner M. Reduction of cyclosporine-induced gingival overgrowth following a change to tacrolimus. A case history involving a liver transplant patient. J Periodontol 1998;69(6):729-32.

Boltchi FE, Rees TD, lacopino AM. Cyclosporine A-induced gingival overgrowth: a comprehensive review. Quintessence Int 1999;30(11):775-83.

Borel JF, Feurer C, Magnee C, Stahelin H. Effects of the new anti-lymphocytic peptide cyclosporin A in animals. Immunology 1977;32(6):1017-25.

Budde K, Fritsche L, Mai I, Bauer S, Smettan S, Waiser J, et al. Clinical pharmacokinetics of tacrolimus in rescue therapy after renal transplantation. Int $\mathrm{J}$ Clin Pharmacol Ther 1996;34(11):493-7.

\footnotetext{
${ }^{1}$ De acordo com Estilo Vancouver. Abreviatura de periódicos segundo base de dados MEDLINE.
} 
Busque S, Demers P, Saint-Louis G, Boily JG, Tousignant J, Lemieux F, et al. [Hypertrichosis and gingival hypertrophy regression in renal transplants following the substitution of cyclosporin by tacrolimus]. Ann Chir 1999;53(8):687-9.

Calne RY, Rolles K, White DJ, Thiru S, Evans DB, Henderson R, et al. Cyclosporin-A in clinical organ grafting. Transplant Proc 1981;13(1 Pt 1):349-58.

Chu FC, Tsang PC, Chan AW, Leung WK, Samaranayake LP, Chan TM. Oral health status, oral microflora, and non-surgical periodontal treatment of renal transplant patients receiving cyclosporin A and FK506. Ann R Australas Coll Dent Surg 2000;15:286-91.

Cox KL, Freese DK. Tacrolimus (FK506): the pros and cons of its use as an immunosuppressant in pediatric liver transplantation. Clin Invest Med 1996;19(5):389-92.

Daley TD, Wysocki GP. Cyclosporine therapy. Its significance to the periodontist. J Periodontol 1984;55(12):708-712.

Daley TD, Wysocki GP, Day C. Clinical and pharmacologic correlations in cyclosporine-induced gingival hyperplasia. Oral Surg Oral Med Oral Pathol 1986;62(4):417-21.

Daly CG. Resolution of cyclosporin A (CsA)-induced gingival enlargement following reduction in CsA dosage. J Clin Periodontol 1992;19(2):143-5.

DeRossi SS, Glick M. Dental considerations for the patient with renal disease receiveing hemodialysis. J Am Dent Assoc 1996;127:211-9.

Drozdzik M, Kurzawski M, Drozdzik A, Kotrych K, Banach J, Pawlik A. Interleukin-6 gene polymorphism in renal transplant patients with and without gingival overgrowth. J Clin Periodontol 2005;32(9):955-8.

Ellis JS, Seymour RA, Steele JG, Robertson P, Butler TJ, Thomason JM. Prevalence of gingival overgrowth induced by calcium channel blockers: a community-based study. J Periodontol 1999;70:63-7.

Ellis JS, Seymour RA, Taylor JJ, Thomason JM. Prevalence of gingival overgrowth in transplant patients immunosuppressed with tacrolimus. J Clin Periodontol 2004;31(2):126-31. 
Friskopp J, Klintmalm G. Gingival enlargement. A comparison between cyclosporine and azathioprine treated renal allograft recipients. Swed Dent J 1986;10(3):85-92.

Gnoatto N. Expressão gênica de proteoglicanos de matriz extracelular no aumento gengival induzido pela ciclosporina A em humanos [Dissertação de Mestrado]. São Paulo: Faculdade de Odontologia da Universidade de São Paulo; 2001.

Goto T, Kino T, Hatanaka H, Okuhara M, Kohsaka M, Aoki H, et al. FK 506: historical perspectives. Transplant Proc 1991;23(6):2713-7.

Hernandez G, Arriba L, Lucas M, de Andres A. Reduction of severe gingival overgrowth in a kidney transplant patient by replacing cyclosporin A with tacrolimus. J Periodontol 2000;71(10):1630-6.

James JA, Boomer S, Maxwell AP, Hull PS, Short CD, Campbell BA, et al. Reduction in gingival overgrowth associated with conversion from cyclosporin $A$ to tacrolimus. $J$ Clin Periodontol 2000;27(2):144-8.

James JA, Jamal S, Hull PS, Macfarlane TV, Campbell BA, Johnson RW, et al. Tacrolimus is not associated with gingival overgrowth in renal transplant patients. $J$ Clin Periodontol 2001;28(9):848-52.

Jones CM. Gingival hyperplasia associated with nifedipine. $\mathrm{Br}$ Dent $\mathrm{J}$ 1986;160(12):416-7.

Kantarci A, Cebeci I, Tuncer O, Carin M, Firatli E. Clinical effects of periodontal therapy on the severity of cyclosporin $A$ introduced gingival hyperplasia. $J$ Periodontol 1999;70(6):587-93.

Kardachi BJ, Newcomb GM. A clinical study of gingival inflammation in renal transplant recipients taking immunosuppressive drugs. J Periodontol 1978;49(6):3079.

King GN, Fullinfaw R, Higgins TS, Walker RJ, Francis DMA, Wiesenfeld D. Gingival hyperplasia in renal allograft recipients receiving cyclosporin-A and calcium antagonists. J Clin Periodontol 1993;20:286-93. 
Kino T, Hatanaka H, Hashimoto M, Nishiyama M, Goto T, Okuhara M, et al. FK-506, a novel immunosuppressant isolated from a Streptomyces. I. Fermentation, isolation, and physico-chemical and biological characteristics. J Antibiot (Tokyo)

1987;40(9):1249-55.

Lambertenghi GD, Santoro F, Polli N, Bruno E, Fumagalli L, Risciotti E. Light and electron microscopic study of cyclosporin-A induced gingival hyperplasia. $J$ Periodontol 1986;57(12):771-5.

Laupacis A, Keown PA, Ulan RA, McKenzie N, Stiller CR. Cyclosporin A: a powerful immunosuppressant. Can Med Assoc J 1982;126(9):1041-6.

Mariani G, Calastrini C, Carinci F, Marzola R, Calura G. Ultrastructural features of cyclosporine A-induced gingival hyperplasia. J Periodontol 1993;64(11):1092-7.

Mariani G, Calastrini C, Carinci F, Bergamini L, Calastrini F, Stabellini G. Ultrastructural and histochemical features of the ground substance in cyclosporin Ainduced gingival overgrowth. J Periodontol 1996;67(1):21-7 .

Mayer AD, Dmitrewski J, Squifflet JP, Besse T, Grabensee B, Klein B, et al. Multicenter randomized trial comparing tacrolimus (FK506) and cyclosporine in the prevention of renal allograft rejection: a report of the European Tacrolimus Multicenter Renal Study Group. Transplantation 1997;64(3):436-43.

McGaw T, Lam S, Coates J. Cyclosporin-induced gingival overgrowth: correlation with dental plaque scores, gingivitis scores, and cyclosporin levels in serum and saliva. Oral Surg Oral Med Oral Pathol 1987;64(3):293-7.

Montebugnoli L, Bernardi F, Magelli C. Cyclosporin A induced gengival overgrowth in heart transplant patients. A cross sectional study. J Clin Periodontol 1996;23(9):86872.

Oettinger-Barak O, Barak S, Machtei EE, Ardekian L, Baruch Y, Peled M. Periodontal changes in liver cirrhosis and post-transplantation patients. I: clinical findings. J Periodontol 2001;72(9):1236-40.

Pernu HE, Pernu LM, Knuuttila ML. Effect of periodontal treatment on gingival overgrowth among cyclosporine A-treated renal transplant recipients. J Periodontol 1993;64(11):1098-100. 
Pernu HE, Pernu LM, Huttunen KR, Nieminen PA, Knuuttila ML. Gingival overgrowth among renal transplant recipients related to immunosuppressive medication and possible local background factors. J Periodontol 1992;63(6):548-53.

Pisanty S, Rahamim E, Ben-Ezra D, Shoshan S. Prolonged systemic administration of cyclosporin A affects gingival epithelium. J Periodontol 1990;61(2):138-41.

Pustiglioni AN. Avaliação clínica periodontal de pacientes transplantados renais submetidos à terapia imunossupressora [dissertação de mestrado]. São Paulo: Faculdade de Odontologia da Universidade de São Paulo; 2001.

Rateitschak-Pluss EM, Hefti A, Lortscher R, Thiel, G. Initial observation that cyclosporin-A induces gingival enlargement in man. J Clin Periodontol 1983;10(3):237-46.

Romito GA. Associação entre crescimento gengival e a condição clínica de pacientes transplantados cardíacos submetidos à terapia com Ciclosporina-A. Estudo Transversal [Tese de Doutorado]. São Paulo: Faculdade de Odontologia da Universidade de São Paulo; 2000.

Romito GA, Lotufo RF, Saraiva L, Pustiglioni AN, Pustiglioni FE, Stolf NA. Superinfecting microorganisms in patients under treatment with cyclosporin-A and its correlation to gingival overgrowth. Pesqui Odontol Bras 2003;17(1):35-40.

Romito GA, Pustiglioni FE, Saraiva L, Pustiglioni AN, Lotufo RF, Stolf NA. Relationship of subgingival and salivary microbiota to gingival overgrowth in heart transplant patients following cyclosporin A therapy. J Periodontol 2004;75(7):918-24.

Ross PJ, Nazif MM, Zullo T, Zitelli B, Guevara P. Effects of Cyclosporin A on gingival status following liver transplantation. ASDC J Dent Child 1989;56(1):56-9.

Rostock MH, Fry HR, Turner JE. Severe gingival overgrowth associated with cyclosporine therapy. J Periodontol 1986;57(5):294-9.

Saraiva L. Avaliação da microbiota subgengival de pacientes transplantados renais antes e após terapia imunossupressora [Dissertação de Mestrado]. São

Paulo: Faculdade de Odontologia da Universidade de São Paulo; 2000.

Saraiva L. Avaliação clínica e microbiológica periodontais de pacientes submetidos à terapia imunossupressora. Estudo longitudinal [Tese de Doutorado]. São Paulo: Faculdade de Odontologia da Universidade de São Paulo; 2002. 
Schuller PD, Freedman HL, Lewis DW. Periodontal status of renal transplant patients receiving immunosuppressive therapy. J Periodontol 1973;44(3):167-70.

Seymour RA, Jacobs DJ. Cyclosporin and the gingival tissues. J Clin Periodontol 1992;19(1):1-11.

Seymour RA, Smith DG. The effect of a plaque control programme on the incidence and severity of cyclosporin-induced gingival changes. J Clin Periodontol 1991;18(2):107-10.

Seymour RA, Smith DG, Rogers SR. The comparative effects of azathioprine and cyclosporin on some gingival health parameters of renal transplant patients. A longitudinal study. J Clin Periodontol 1987;14(10):610-3.

Seymour RA, Smith DG, Turnbull DN. The effects of phenytoin and sodium valproate on the periodontal health of adult epileptic patients. J Clin Periodontol 1985;12:413-9.

Shapiro R, Jordan M, Scantlebury V, Vivas C, Fung J, McCauley J, et al. A prospective, randomized trial of FK-506 in renal transplantation - a comparison between double- and triple-drug therapy. Clin Transplant 1994;8(6):508-15.

Shield CF, McGrath MM, Goss TF. Assessment of health-related quality of life in kidney transplant patients receiving tacrolimus (FK506)-based versus cyclosporinebased immunosuppression. FK506 Kidney Transplant Study Group. Transplantation 1997;64(12):1738-43.

Silness J, Löe H. Periodontal disease in pregnancy. II. Correlation between oral hygiene and periodontal condition. Acta Odontol Scand 1964;22:121-35.

Somacarrera ML, Hernandez G, Acero J, Moskow BS. Factors related to the incidence and severity of cyclosporin-induced gingival overgrowth in transplant patients. A longitudinal study. J Periodontol 1994;65(7):671-5.

Starzl TE, Fung J, Jordan M, Shapiro R, Tzakis A, McCauley J, et al. Kidney transplantation under FK 506. JAMA 1990;264(1):63-7.

Thomason JM, Seymour RA, Rice N. The prevalence and severity of cyclosporin and nifedipine-induced gingival overgrowth. J Clin Periodontol 1993;20(1):37-40. 
Thomason JM, Seymour RA, Ellis JS. Risk factors for gingival overgrowth in patients medicated with ciclosporin in the absence of calcium channel blockers. J Clin Periodontol 2005;32(3):273-9.

Thomason JM, Ellis JS, Kelly PJ, Seymour RA. Nifedipine pharmacological variables as risk factors for gingival overgrowth in organ-transplant patients. Clin Oral Invest 1997;1:35-9.

Thorp M, DeMattos A, Bennett W, Barry J, Norman D. The effect of conversion from cyclosporine to tacrolimus on gingival hyperplasia, hirsutism and cholesterol. Transplantation 2000;69(6):1218-20.

Tyldesley WR, Rotter E. Gingival hyperplasia induced by cyclosporin-A. Br Dent J 1984;157(9):305-9.

Uemoto S, Tanaka K, Honda K, Tokunaga Y, Sano K, Katoh H, et al. Experience with FK506 in living-related liver transplantation. Transplantation 1993;55(2):288-92.

Wysocki GP, Gretzinger HA, Laupacis A, Ulan RA, Stiller CR. Fibrous hyperplasia of the gingiva: a side effect of cyclosporin A therapy. Oral Surg Oral Med Oral Pathol 1983;55(3):274-8. 
APÊNDICE A - Termo de consentimento esclarecido para pesquisa clínica

\section{UNIVERSIDADE DE SÃO PAULO \\ FACULDADE DE ODONTOLOGIA \\ DEPARTAMENTO DE ESTOMATOLOGIA - DISCIPLINA DE PERIODONTIA \\ TERMO DE CONSENTIMENTO LIVRE ESCLARECIDO}

Este documento tem intenção de informar, esclarecer e obter sua autorização para participar da Pesquisa científica intitulada "Avaliação clínica do crescimento gengival induzido por Ciclosporina A e Tacrolimus em indivíduos transplantados renais. Estudo longitudinal." que será desenvolvida pelo Dr. Ricardo Takiy Sekiguchi, Profa. Dra. Luciana Saraiva e pelo Prof. Dr. Roberto Fraga Moreira Lotufo.

Este estudo tem o objetivo de avaliar o crescimento da gengiva que ocorre em muitos pacientes devido aos medicamentos utilizados após o transplante renal. A importância da sua contribuição neste estudo é nos ajudar no conhecimento dos efeitos desses medicamentos na gengiva, uma vez que o (a) Sr. (Sra.) utilizará esses medicamentos receitados pelo médico após seu transplante renal para evitar a rejeição do novo órgão.

Para esta avaliação, o (a) Sr. (Sra.) será examinado por um cirurgião dentista especialista em gengiva nos seguintes períodos: antes do transplante, 1 mês, 3 meses, 6 meses e 12 meses após o transplante (5 consultas). Em todas as consultas será feito um exame dos dentes e da gengiva, será passado instruções de escovação dental e uso do fio dental e ainda será realizado uma profilaxia (higienização profissional) dos dentes.

Todas as consultas serão realizadas na Clínica da APCD (Associação Paulista de Cirurgiões Dentistas) - Regional Vila Mariana (localizada entre o metrô V. Mariana e o metrô Ana Rosa), RUA CONCEIÇÃO VELOSO, 203 - Vila Mariana - São Paulo - SP, tel (11) 5549-3261 / 5575-6930.

O (a) Sr. (Sra.) não receberá compensação financeira por sua participação no estudo. Sua identidade será mantida em sigilo e o Sr. (Sra.) terá a liberdade de se recusar a participar ou de se retirar da pesquisa a qualquer momento que desejar, mesmo após ela Ter sido iniciada, sem perda de qualquer benefício que esteja recebendo. 
O (a) Sr. (Sra.) poderá esclarecer qualquer dúvida ou qualquer problema que surja entrando em contato com o Dr. Ricardo Takiy Sekiguchi.

Declaro Ter sido esclarecido dos objetivos e riscos deste estudo e concordo em participar do mesmo.

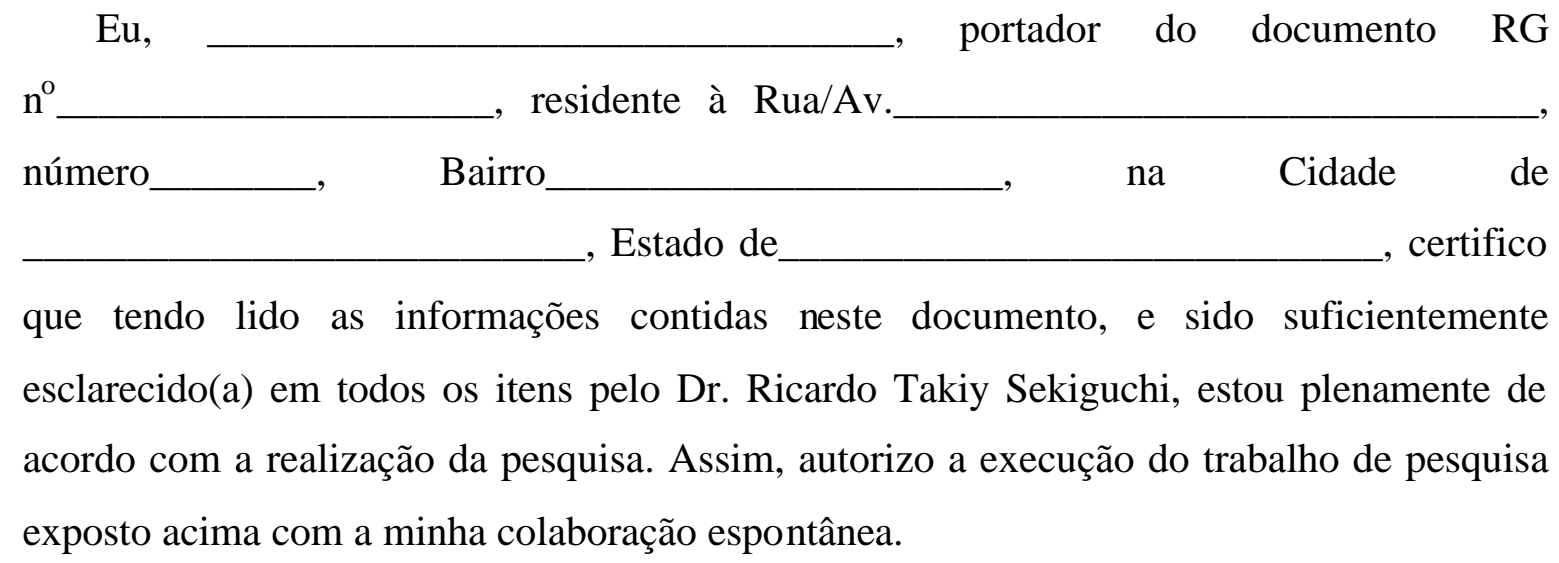

Assinatura do participante:

Data:

Declaro ter obtido o consentimento livre e esclarecido do participante para meu estudo.

Assinatura:

Investigador principal: Ricardo Takiy Sekiguchi

CRO 77.489 


\title{
UNIVERSIDADE DE SÃO PAULO FACULDADE DE ODONTOLOGIA
}

\author{
PARECER $n^{\circ} 139 / 02$ \\ Protocolo 135/02
}

Com base em parecer de relator, o Comitê de Ética em Pesquisa, APROVOU o protocolo de pesquisa "Avaliação clínica do crescimento gengival induzido por Ciclosporina A e Tacrolimus em indivíduos transplantados renais. Estudo Iongitudinal", de responsabilidade da pesquisador Ricardo Takiy Sekiguchi, sob orientação do Professor Doutor Roberto Fraga Moreira Lotufo.

Tendo em vista a legislação vigente, devem ser encaminhados a este Comitê relatórios referentes ao andamento da pesquisa em 11 de janeiro de 2003 e em 11 de julho de 2003. Ao término da pesquisa, cópia do trabalho deve ser encaminhada a este CEP.

São Paulo, 11 de julho de 2002

(e)duifue

Profa.Dra. Célia Regina Martins Delgado Rodrigues

Coordenadora do CEP-FOUSP 
ANEXO B - Carta de aprovação do Comitê de Ética em Pesquisa do Hospital do Rim e Hipertensão Universidade Federal de São Paulo
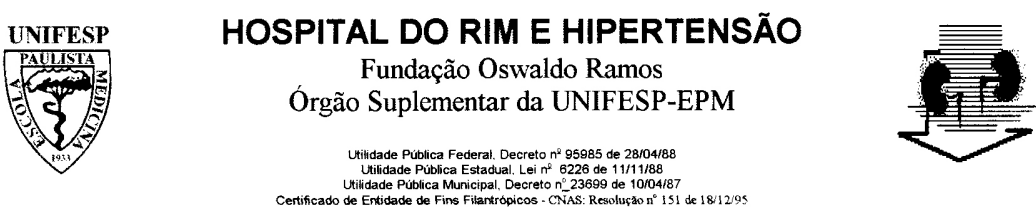

São Paulo, 09 de maio de 2005.

IImo. Sr.

Dr. Ricardo Takiy Sekiguchi

Ref.: Protocolo No. 089 intitulado "Avaliação Clínica do Crescimento Gengival induzido por Medicamentos Imunossupressores Ciclosporina A e Tacrolimus em Pacientes Transplantados Renais."

Prezado Doutor,

O Comitê de Ética em Pesquisa do Hospital do Rim e Hipertensão - Fundação Oswaldo Ramos está ciente e aprova a mudança do investigador principal do estudo supra citado, antes conduzido pela Dra. Luciana Safioti e que agora passa a ter como investigador principal o Dr. Ricardo Takiy Sekiguchi.

Reafirmamos também que este estudo foi aprovado em 31 de julho de 2002

Atenciosamente

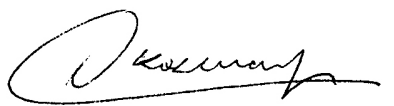

Prof. Dr. Osvaldo Kohlmann Junior

Presidente do Comitê de Ética em Pesquisa

Hospital do Rim e Hipertensão

Fundação Oswaldo Ramos 
ANEXO C - Ficha de anamnese da F.O.U.S.P.

PACIENTE:

R.G.:

\section{SAÚDE GERAL}

01. Está em tratamento médico?

02. Foi submetido a alguma cirurgia?

03. Teve ou tem alguma destas doenças:

- Hepatites

- Tuberculose

- Problema Cardíaco

- Diabetes

- Febre Reumática

05. Toma anticoagulante (AAS)?

06. É fumante?

07. Pressão alta?

sim ( ) não () Quantos?

08 . Sofre dos rins ou bexiga?

09. Tem com freqüência algum tipo de hemorragia?

10. Aparecem manchas roxas no corpo com freqüência?

11. Anemia?

12. Tem alguma alergia?

13. Alergia a quê?

14. Já recebeu transfusão de sangue?

15. Tem doença sexualmente transmissivel (AIDS)?

16. Tem tonturas?

17. Tem convulsões?

18. Menstruaçăo está normal?

19. Está grávida?

20. Toma anticoncepcional?

21. Está na menopausa?

22. Medicamentos em uso

Histórico de distūrbio renal

Tempo de Hemodiálise:

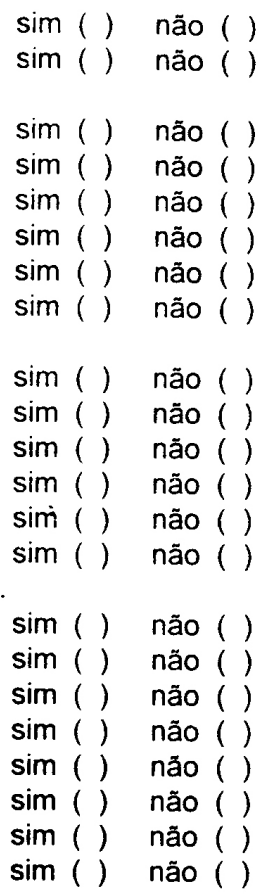

\section{PARTE ODONTOLÓGICA}

01. Queixa do Paciente:

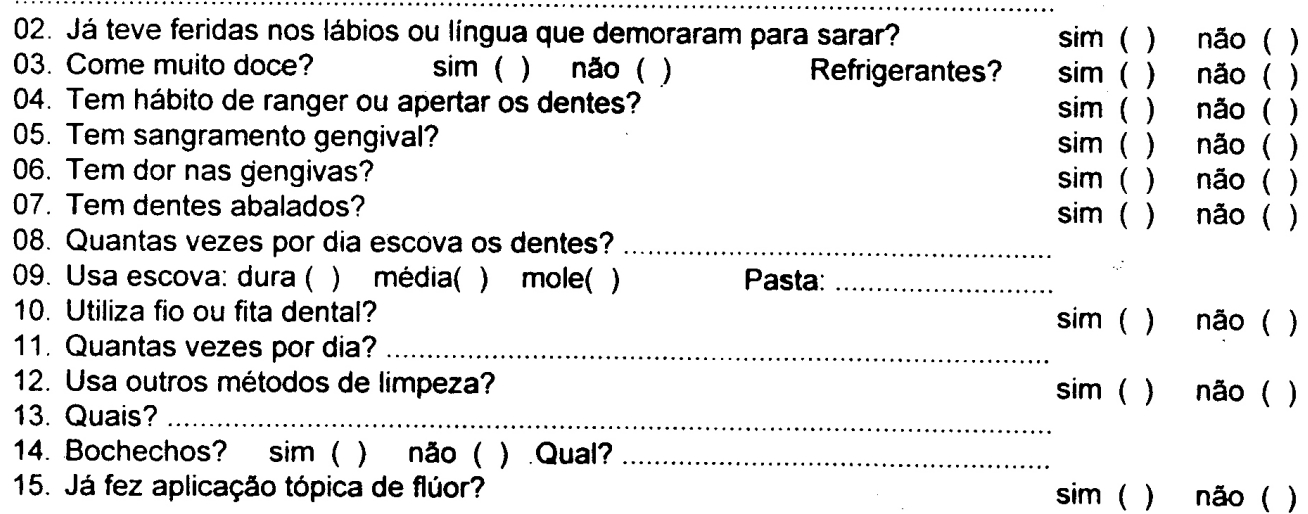


ANEXO D - Ficha dos parâmetros clínicos periodontais da F.O.U.S.P.

\section{UNIVERSIDADE DE SAO PAULO - FACULDADE DE ODONTOLOGIA DEPARTAMENTO DE ESTOMATOLOGIA DISCIPLINAS DE PERIODONTIA}

PACIENTE:

IDADE:

SEXO: RAÇA: $N^{\circ}$ :

FICHA INICIAL ( )

REAVALIAÇÃOi )

FINA.L ( )

$\mathrm{UEC}-\mathrm{MG}$
$\mathrm{PCS}-\mathrm{SS}$ $\mathrm{NCI}$
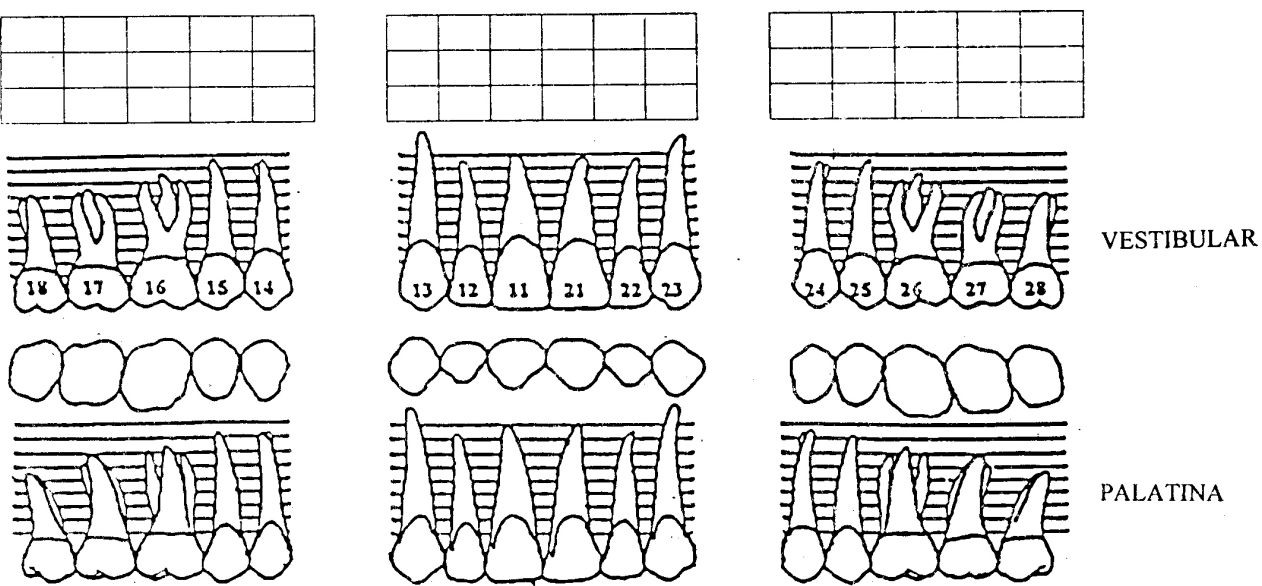

UEC - MG
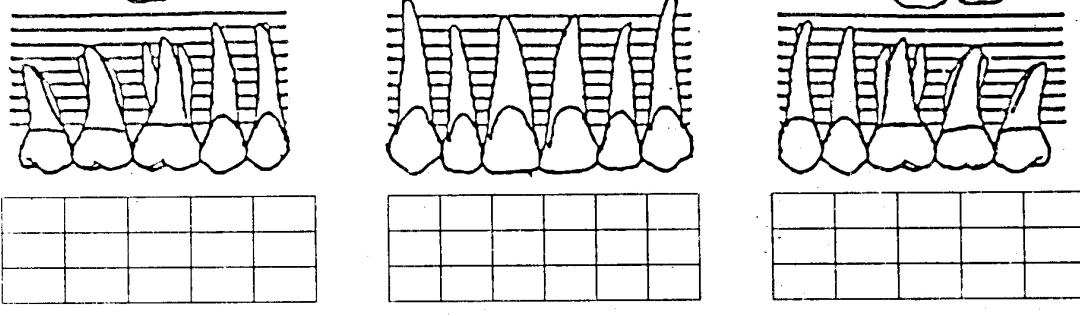

PALATINA

$\mathrm{PCS}-\mathrm{SS}$
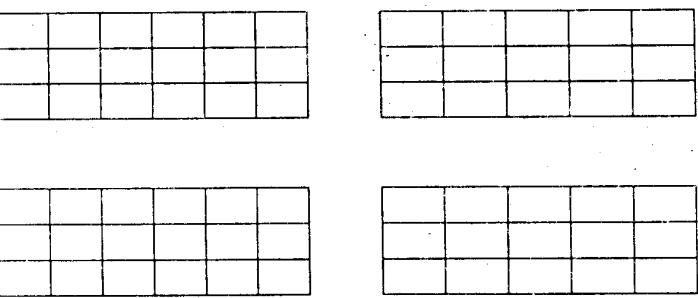

UEC - MG

PCS - SS
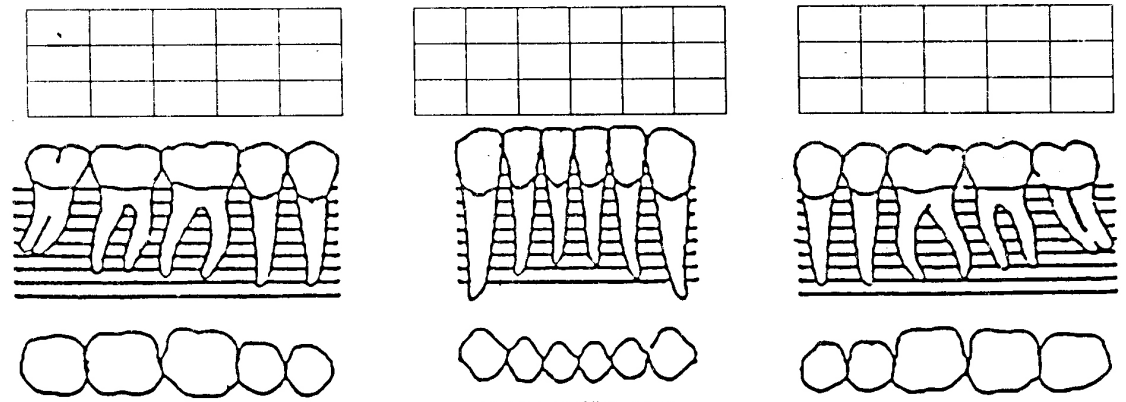

LINGUAL
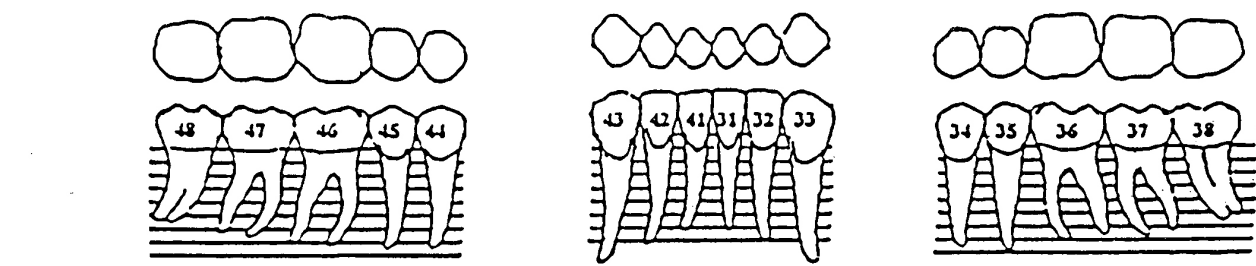

UEC - MG
PCS - SS
NCI
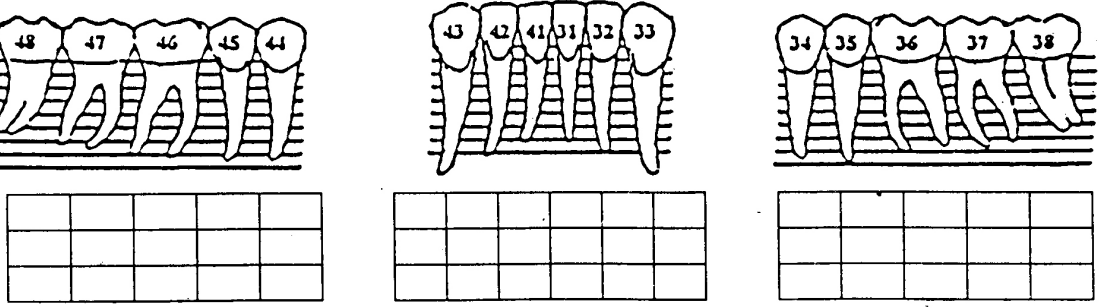

vESTIBULAR

Indice de

Sangramento:
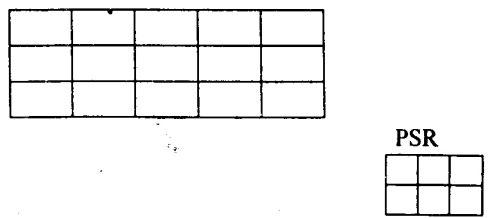